Atmos. Chem. Phys., 13, 9939-9970, 2013

www.atmos-chem-phys.net/13/9939/2013/

doi:10.5194/acp-13-9939-2013

(c) Author(s) 2013. CC Attribution 3.0 License.

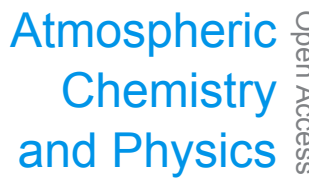

\title{
The global impact of the transport sectors on atmospheric aerosol: simulations for year 2000 emissions
}

\author{
M. Righi, J. Hendricks, and R. Sausen \\ Deutsches Zentrum für Luft- und Raumfahrt (DLR), Institut für Physik der Atmosphäre, Oberpfaffenhofen, Germany \\ Correspondence to: M. Righi (mattia.righi@dlr.de)
}

Received: 3 April 2013 - Published in Atmos. Chem. Phys. Discuss.: 17 May 2013

Revised: 9 August 2013 - Accepted: 21 August 2013 - Published: 9 October 2013

\begin{abstract}
We use the EMAC (ECHAM/MESSy Atmospheric Chemistry) global model with the aerosol module MADE (Modal Aerosol Dynamics model for Europe, adapted for global applications) to quantify the impact of transport emissions (land transport, shipping and aviation) on the global aerosol. We consider a present-day (2000) scenario according to the CMIP5 (Climate Model Intercomparison Project Phase 5) emission data set developed in support of the IPCC (Intergovernmental Panel on Climate Change) Fifth Assessment Report. The model takes into account particle mass and number emissions: The latter are derived from mass emissions under different assumptions on the size distribution of particles emitted by the three transport sectors. Additional sensitivity experiments are performed to quantify the effects of the uncertainties behind such assumptions. The model simulations show that the impact of the transport sectors closely matches the emission patterns. Land transport is the most important source of black carbon (BC) pollution in the USA, Europe and the Arabian Peninsula, contributing up to $60-70 \%$ of the total surface-level BC concentration in these regions. Shipping contributes about $40-60 \%$ of the total aerosol sulfate surface-level concentration along the most-traveled routes of the northern Atlantic and northern Pacific oceans, with a significant impact $(\sim 10-20 \%)$ along the coastlines. Aviation mostly affects aerosol number, contributing about $30-40 \%$ of the particle number concentration in the northern midlatitudes' upper troposphere $(7-12 \mathrm{~km})$, although significant effects are also simulated at the ground, due to the emissions from landing and take-off cycles. The transport-induced perturbations to the particle number concentrations are very sensitive to the assumptions on the size distribution of emitted particles, with the largest uncertainties (about one order of magnitude) obtained for the land trans-
\end{abstract}

port sector. The simulated climate impacts, due to aerosol direct and indirect effects, are strongest for the shipping sector, in the range of -222.0 to $-153.3 \mathrm{~mW} \mathrm{~m}^{-2}$, as a consequence of the large impact of sulfate aerosol on low marine clouds and their optical properties.

\section{Introduction}

Emissions from the land transport, shipping and aviation sectors have an important effect on atmospheric composition, which results in significant impacts on air quality and climate. According to the IPCC Fourth Assessment Report (Kahn Ribeiro et al., 2007), transport was responsible for $23 \%$ of global energy-related (mainly energy production, industry, transport, residential and services) $\mathrm{CO}_{2}$ emissions in $2004\left(6.3 \mathrm{Gt}^{\mathrm{CO}_{2}}\right)$ and road transport shared the dominant part $(74 \%)$ of this value. The greenhouse gas emissions from the transport sectors have increased more rapidly than those of other energy-consuming sectors in the recent decade: the contribution from transport to the total $\mathrm{CO}_{2}$-equivalent emissions (i.e., greenhouse gases considered by the Kyoto protocol) grew by $32 \%$ from 1990 to 2007 in the EU-15 countries, although total anthropogenic $\mathrm{CO}_{2}$-equivalent emissions decreased by $5.5 \%$ in these countries (Sausen, 2010). According to Kahn Ribeiro et al. (2007), the energy use by global transport is expected to grow further, by about $80 \%$ until 2030 with respect to 2007 levels, at a rate of more than $2 \%$ per year. Developing countries and growing economies will experience the strongest increase, shifting their share from 36 to $46 \%$ between 2007 and 2030 (non-OECD countries). Hence, the effects of transport-related emissions on atmosphere and climate deserve closer attention. 
The combustion of fossil fuels, which supplied $95 \%$ of the energy used in transport in 2001 (Kahn Ribeiro et al., 2007), leads also to the emission of various types of particulate matter (PM). Aerosol particles can impact climate, by directly interacting with incoming solar radiation and by modifying the microphysical properties and lifetime of clouds (Lohmann and Feichter, 2005). These effects alter Earth's radiation budget, by reducing or increasing the amount of energy absorbed by the system (Sausen et al., 2012). Global model studies reveal that aerosol emissions from the land transport sector induce a positive direct radiative forcing $(\mathrm{RF})$. According to the assessment report by Uherek et al. (2010), this is in the range of $3-31.7 \mathrm{~mW} \mathrm{~m}^{-2}$ (year 2000) and is mainly due to absorption by black carbon, but these numbers do not include cloud effects. The shipping sector, on the other hand, is characterized by large emission of $\mathrm{SO}_{2}$, due to the high sulfur content of ship fuels. The oxidation of $\mathrm{SO}_{2}$ can lead to the formation of sulfate aerosol particles, which act as cloud condensation nuclei and can therefore modify the microphysical structure of clouds and increase their reflectivity (first indirect or cloud albedo effect; Twomey, 1977). Model studies (Capaldo et al., 1999; Lauer et al., 2007) suggest that this effect results in a significant cooling, which largely dominates the aerosolinduced global RF from this sector, but the uncertainties inherent to this result are high. According to the assessment by Eyring et al. (2010), the global indirect RF from shipping is in the range of -600 to $-38 \mathrm{~mW} \mathrm{~m}^{-2}$ (year 2000). The direct RF of aviation-induced aerosols is probably small compared to other aviation-related effects, such as contrail cirrus (Sausen et al., 2005; Lee et al., 2009). A recent study by Unger (2011) suggests a direct RF of only a few $\mathrm{mW} \mathrm{m}^{-2}$. However, it is currently debated whether aviation-induced aerosol could affect cirrus cloud formation leading to modifications of cirrus properties (Liu et al., 2009; Hendricks et al., 2011). Resulting radiative effects are estimated to be of the order of up to $100 \mathrm{~mW} \mathrm{~m}^{-2}$, although there is no consensus on the sign.

Aerosol particles also have detrimental consequences for air quality and human health. Fine particles, with diameters smaller than $2.5 \mu \mathrm{m}$, are of particular concern, given their ability to penetrate the human respiratory system (Fang et al., 2013). According to the World Health Organization, more than 2 million global premature deaths each year are attributable to urban air pollution and more than half of them are occurring in developing countries (see Uherek et al., 2010, and references therein). Transport-related urban air pollution can mainly be attributed to land transport emissions, although shipping also increases the aerosol concentration, especially in the coastal areas and in the vicinity of major harbors (Eyring et al., 2010). Corbett et al. (2007) estimated that about 60000 premature deaths each year due to cardiopulmonary and lung cancer diseases can be attributed to PM emission from shipping. Barrett et al. (2010) investigated the health impact of aircraft emissions, considering also the effects of emissions from aircraft at cruise altitude.
They suggest that about 10000 premature deaths per year are related to this source, which corresponds to about $1 \%$ of airquality-related premature deaths from all sources.

The global impact of the transport sectors on atmosphere and climate has been analyzed in several previous publications, e.g., in the ATTICA assessment reports (Sausen, 2010; Fuglestvedt et al., 2010; Lee et al., 2010; Eyring et al., 2010; Uherek et al., 2010). Studies consistently comparing the effects of land-based transport, shipping, and aviation mainly focused on atmospheric gas-phase chemistry, particularly of ozone (Hoor et al., 2009; Koffi et al., 2010; Hodnebrog et al., 2012) or on the RF and climate impacts (Fuglestvedt et al., 2008; Skeie et al., 2009; Balkanski et al., 2010; Myhre et al., 2011; Bauer and Menon, 2012; Olivié et al., 2012). A corresponding analysis on the details of transport-induced global perturbations of specific aerosol compounds, aerosol particle number concentration and size distribution is desirable.

Hence, the goal of the present study is to provide a comprehensive model-based assessment of the impacts of the individual transport modes (land transport, shipping and aviation) on global aerosol. The EMAC-MADE global aerosol model is applied, which is capable to simultaneously track aerosol mass and number concentrations as well as the particle size distributions. This allows us to quantify aerosol impacts in terms of mass and particle number concentration, which are both essential indicators for air quality and climate issues. The applied version of the model also includes couplings of the aerosol microphysics to radiation and cloud schemes, which makes it possible to quantify the aerosol impact on Earth's radiation budget.

In order to assess uncertainties inherent in the simulations, a set of targeted sensitivity experiments is carried out. A possible source of uncertainty is related to the assumptions made to estimate particle number emissions from the aerosol mass emission rates. The number-to-mass ratio of emitted particle populations can significantly change in dispersing exhaust plumes (Kärcher et al., 2007; Petzold et al., 2008). Therefore, the size-distribution parameters to be assumed in the large-scale simulation in order to characterize the numberto-mass ratio of particles emitted from different sources in different size ranges have to be decided. Since the model results can be significantly affected by these ratios (Righi et al., 2011; Peters et al., 2012), sensitivity studies with different assumptions about the size distribution of emitted particles are performed.

Moreover, the effects of varying assumptions about the aviation fuel sulfur content are studied. Simulations with reduced sulfur emissions are performed, motivated by a previous assessment by Unger (2011), who suggested the use of desulfurized jet fuels as an effective mitigation strategy to reduce the climate effect of aviation. The impact of lowsulfur shipping fuels has been extensively explored in a previous work (Righi et al., 2011), whereas for land transport this issue is of limited interest given the very low sulfur content of present-day vehicle fuels (Uherek et al., 2010). Sulfur 
reduction scenarios for these two sectors will therefore not be further analyzed in the present paper.

Finally, an additional set of simulations is devoted to the analysis of possible non-linearities in the aerosol effects from transport, a topic that has not been discussed previously. The impact of each sector is quantified by performing a reference simulation (including all emission sources) and comparing it with sensitivity experiments, in which the emissions from each individual transport sector are switched off (100\% perturbation method). As shown by Hoor et al. (2009) for transport-induced ozone perturbations, this may lead to misinterpretations since the concentration response can show a highly non-linear dependence on the magnitude of the emission perturbation. In such a case, the sum of the concentration changes obtained by applying the $100 \%$ perturbation method to the individual sectors can strongly differ from the effect of neglecting transport emissions at all (see also Grewe et al., 2010). To cope with such non-linearities, Hoor et al. (2009) proposed the so-called small-perturbation method, by reducing the emissions in each sector by a small fraction (5\% in their case) and then scaling the resulting impact to the total $(100 \%)$. Although they focused on ozone perturbations which are known to be highly non-linear, it is worthwhile to apply this method as an alternative to check for such non-linearities in the aerosol case as well.

In the present paper we focus on present-day (year 2000) emissions. The analysis of future impacts for the IPCC representative concentration pathways (RCP; Moss et al., 2010), with attention to different regions (developed versus developing countries and growing economies), is intended to be the subject of a follow-up study.

The present paper is organized as follows: The description of the emission setup is provided in Sect. 2. Section 3 contains a summary of the performed experiments, including the related assumptions on size distributions of emitted aerosol particles. Simulated total aerosol concentrations (resulting from all emission sources) are presented in Sect. 4. The impacts of transport on aerosol distribution, including mass, number and size, are presented and discussed in Sects. 5 and 6 , whereas the transport-induced changes in the radiation budget are covered in Sect. 7. Finally, non-linearities are analyzed in Sect. 8 and Sect. 9 summarizes the conclusions of this work. The EMAC-MADE global aerosol model is described in Appendix A, together with a short discussion about its evaluation. More details about the assumed size distributions of emitted particles are given in Appendix B. Appendix $C$ provides the values of the transport-induced aerosol radiative forcing, which are presented as a barplot in the text. Acronyms and abbreviations used throughout the paper are listed in Appendix D.

\section{Emission setup}

\subsection{Mass emission fluxes}

The anthropogenic and biomass burning emissions for the year 2000 from the recent data set by Lamarque et al. (2010) are used as input to all simulations presented here. They include yearly and monthly emissions at $0.5^{\circ}$ resolution for gases $\left(\mathrm{CO}, \mathrm{NO}_{\mathrm{x}}\right.$, non-methane hydrocarbons (NMHCs), $\mathrm{NH}_{4}$ and $\mathrm{SO}_{2}$ ) and aerosols (black and organic carbon) for 12 sectors (biomass burning and anthropogenic sources, including land-based transport, international shipping and aviation as individual sectors). The NMHC speciation is realized according to the speciation fractions by von Kuhlmann et al. (2003), which are consistent with the chemical mechanism of EMAC. The injection heights for the anthropogenic sectors (6 levels in the range $45-800 \mathrm{~m}$ ) and for biomass burning (6 levels in the range $0-6 \mathrm{~km})$ are chosen according to Pozzer et al. (2009) and to the AeroCom recommendations (Dentener et al., 2006, hereafter D06), respectively. Aviation emissions are distributed among 23 equally spaced altitude levels in the range $0-15 \mathrm{~km}$, as in the QUANTIFY inventory (Lee et al., 2005).

Primary $\mathrm{SO}_{4}$ emissions are derived as the $2.5 \%$ mass fraction of $\mathrm{SO}_{2}$ emissions (D06), with the exception of aviation, for which a $2.2 \%$ fraction is assumed following Jurkat et al. (2011). Primary $\mathrm{SO}_{4}$ emissions from the anthropogenic nontransport sectors are neglected, following D06. Organic matter $(\mathrm{OM})$ is scaled from organic carbon (OC) assuming a ratio $\mathrm{OM} / \mathrm{OC}=1.4$ (D06). Emissions of wind-driven dust and of sulfur from volcanic activity (both explosive and continuously degassing events) are prescribed with the offline fields provided by AeroCom (D06). Wind-speed dependent emission of sea salt $(\mathrm{NaCl})$ is computed online, according to the model of Guelle et al. (2001). Our setup also includes emissions of DMS (Spiro et al., 1992) and of biogenic sources, including secondary organic aerosols (Guenther et al., 1995).

Sulfur emissions from aviation, not available in the Lamarque et al. (2010) data set, are included by simply scaling aircraft $\mathrm{BC}$ emissions by the corresponding emission factors:

$F_{\mathrm{SO}_{2}}=F_{\mathrm{BC}} \frac{\mathrm{EF}\left(\mathrm{SO}_{2}\right)}{\mathrm{EF}(\mathrm{BC})}$,

where $F$ indicates the emission flux (emitted mass per unit time per unit volume) and EF is the emission factor (emitted mass per unit mass of burnt fuel). This simplified scaling neglects the fact that aircraft sulfur and black carbon emissions are not strictly proportional: While the emissions of black carbon depend, e.g., on fuel flow and engine type, the sulfur emissions are primarily a function of the fuel composition. The BC emission factor is estimated from the QUANTIFY inventory (Lee et al., 2005) as the volume-weighted ratio between emission flux and fuel consumption at each altitude, on a yearly-average basis. This results in an emission 
factor between 0.01 and $0.05 \mathrm{~g}(\mathrm{BC}) \mathrm{kg}_{\text {fuel }}^{-1}$ (depending on the altitude), consistent with the 0.025 value suggested by Lee et al. (2010). For the $\mathrm{SO}_{2}$ emission factor, the value of $0.8 \mathrm{~g}\left(\mathrm{SO}_{2}\right) \mathrm{kg}_{\text {fuel }}^{-1}$ given in Lee et al. (2010) is adopted. As mentioned above, $2.2 \%$ of this emission is assigned to primary $\mathrm{SO}_{4}$, following Jurkat et al. (2011). Emissions of volatile organic compounds from aircraft, which could also contribute to particle formation, are neglected since the corresponding emission factors are quite uncertain (Lee et al., 2010).

The global year 2000 emissions for the most relevant sectors and species and their relative contribution with respect to the total are summarized in Fig. 1.

\subsection{Number emission fluxes and size distributions of emitted particles}

The aerosol module MADE employed in the present study describes the aerosol population using three log-normally distributed size modes (Aitken, accumulation and coarse mode) and is able to simulate both the aerosol mass and number concentration (see Appendix A1 for a detailed description). For this reason, the aerosol emissions must be split into the size modes and number emissions must be provided as well. This requires the assumption of a size distribution for the emitted particles. Here we consider prescribed size distributions expressed by a superposition of several size modes (Table 1). The size distributions assumed for anthropogenic particles include a nucleation mode, an Aitken mode, and an accumulation mode. The distribution within each individual mode $i$ is also described by the log-normal function, characterized by three parameters (see e.g., Seinfeld and Pandis, 1998): The total number concentration $N_{i}$ of particles in the mode, their median diameter $D_{\mathrm{g}, i}$ (equivalent to the geometric mean diameter) and the geometric standard deviation $\sigma_{\mathrm{g}, i}$.

The total volume concentration of the particles within the mode $i$ can be calculated as

$$
V_{i}=\frac{\pi}{6} N_{i} D_{g, i}^{3} \exp \left(\frac{9}{2} \ln ^{2} \sigma_{\mathrm{g}, i}\right)
$$

The splitting of the total emitted mass flux $F_{M}$ among the size modes of the model can be estimated from the relative volume concentrations $f_{V, i}=V_{i} / \sum_{i} V_{i}$ of the corresponding emission modes as

$$
F_{M, i}=f_{V, i} F_{M} \text {. }
$$

Since the model subsumes nucleation and Aitken mode particles in a single mode (the model's Aitken mode), the emitted particles of these two size ranges are both assigned to the model's Aitken mode. By converting the emitted mass flux $F_{M, i}$ to an emitted volume flux $F_{V, i}$, the corresponding particle number emission flux $F_{N, i}$ can be calculated as

$$
F_{N, i}=\frac{6}{\pi} \frac{F_{V, i}}{D_{\mathrm{g}, i}^{3} \exp \left(\frac{9}{2} \ln ^{2} \sigma_{\mathrm{g}, i}\right)} .
$$

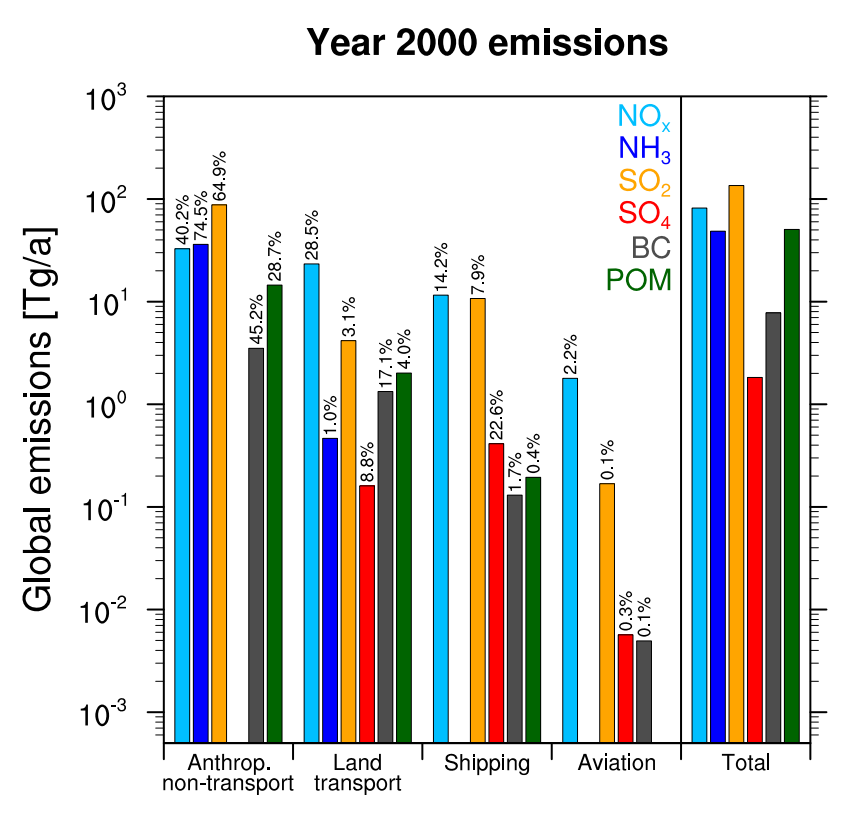

Fig. 1. Global emissions in the year 2000 for the anthropogenic sectors. The relative contribution to the total (including biomass burning and natural sources which are not shown here) is given on top of each bar. Units are $\operatorname{Tg}$ (species) $\mathrm{a}^{-1}$ and $\mathrm{Tg}(\mathrm{NO}) \mathrm{a}^{-1}$ for $\mathrm{NO}_{\mathrm{x}}$.

In many cases, the emission of aerosol particles occurs on scales which cannot be resolved by large-scale models like EMAC. During the dispersion from the sources to larger scales the particle size distribution can undergo changes due to aging processes. As an example, Petzold et al. (2008) observed that the contribution of ultra-fine particles to the total number of particles measured in ship exhaust plumes decreases with plume age. They attribute these changes mainly to particle coagulation. To implicitly include subgrid-scale aging processes in large-scale model simulations, size distributions of aged exhaust particles can be assumed to characterize the number and size of emitted particles. However, it is questionable which state of particle aging should be taken as representative for global model applications. One of the goals of this study is to explore the consequences of such uncertainties for the large-scale transport-induced aerosol perturbations simulated here. To achieve this, we perform several sensitivity studies, varying the size distributions assumed for the particles emitted by each individual transport sector. We consider, for example, size distributions representative for roadside, urban background air, or ship and aircraft exhaust plumes of different ages. For each of the three sectors, a reference and two alternative size distributions are considered. These distributions are described in Sect. 3 and in Appendix $B$. The parameters of the underlying measured size distributions are given in Table 1. 
Table 1. Parameters of the size distributions considered to derive particle number emission fluxes from the mass fluxes of anthropogenic and biomass burning emissions. The nucleation, Aitken and accumulation modes are indicated by NUC, AKN and ACC, respectively. The parameters are used to assign the emitted particle mass to the different size modes and to calculate the corresponding number of emitted particles. The nucleation and Aitken modes are both assigned to the Aitken mode of MADE.

\begin{tabular}{|c|c|c|c|c|c|c|c|c|c|c|}
\hline \multirow[b]{2}{*}{ Name } & \multirow[b]{2}{*}{ Reference } & \multicolumn{3}{|c|}{$N_{i}\left[\mathrm{~cm}^{-3}\right]$} & \multicolumn{3}{|c|}{$D_{\mathrm{g}, i}[\mu \mathrm{m}]$} & \multicolumn{3}{|c|}{$\sigma_{\mathrm{g}, i}$} \\
\hline & & NUC & $\mathrm{AKN}$ & ACC & NUC & $\mathrm{AKN}$ & ACC & NUC & $\mathrm{AKN}$ & ACC \\
\hline D06 & Dentener et al. (2006) & - & - & - & - & 0.030 & 0.080 & - & 1.80 & 1.80 \\
\hline B09 & Birmili et al. (2009) & 4000 & 2300 & 1500 & 0.018 & 0.058 & 0.138 & 1.70 & 1.58 & 1.59 \\
\hline AGED1 & Righi et al. (2011) & - & 12800 & 8 & - & 0.058 & 0.310 & - & 1.52 & 1.145 \\
\hline AGED2 & Righi et al. (2011) & - & 6700 & 50 & - & 0.070 & 0.260 & - & 1.45 & 1.25 \\
\hline P99 & Petzold et al. (1999) & - & $9 \times 10^{6}$ & 3000 & - & 0.025 & 0.150 & - & 1.55 & 1.65 \\
\hline K07 & Kärcher et al. (2007) & - & - & - & 0.0025 & - & - & 1.70 & - & - \\
\hline
\end{tabular}

\section{Model simulations}

The simulations presented in this paper are performed with the ECHAM/Messy Atmospheric Chemistry (EMAC) general circulation model (Roeckner et al., 2006; Jöckel et al., 2006), coupled to the aerosol module MADE (Lauer et al., 2005, 2007). A detailed description of the EMAC-MADE global model system is provided in Appendix A, including also an overview of the model evaluation.

Each experiment covers a period of $10 \mathrm{yr}$ (plus $1 \mathrm{yr}$ spinup) from 1996 to 2005. To minimize the differences in the dynamics of the experiments, model dynamics (vorticity, divergence, temperature, and surface pressure) is nudged (Jeuken et al., 1996) to the operational analysis data of the European Centre for Medium-range Weather Forecasts (ECMWF). Boundary conditions for long-lived species $\left(\mathrm{CO}_{2}\right.$ and $\mathrm{CH}_{4}$ ) are provided to the model via the TNUDGE submodel (Kerkweg et al., 2006b) using the observed mixing ratios from the AGAGE database (Prinn et al., 2000).

In the present study, the impact of transport sector emissions on aerosol and climate is quantified by means of a $100 \%$ perturbation method. The effect of a given sector is estimated as the difference between the reference simulation (REF), which includes all emission sources, and a sensitivity experiment in which emissions from the given sector are completely switched off.

As shown by Hoor et al. (2009), for the special case of transport-induced ozone production, the above approach can lead to an inaccurate estimate of the transport impacts, due to the non-linearities arising in the chemical system. To estimate the possible effects of such non-linearities, Hoor et al. (2009) alternatively proposed to use a small-scale perturbation approach, by reducing the emission of each specific source by a small fraction ( $5 \%$ in their case) and then scaling the resulting perturbation to $100 \%$. Although non-linearities in the aerosol microphysics are expected to be smaller than the non-linearities related to ozone perturbations, we perform an additional set of three simulations, where emissions in each sector are reduced by $50 \%$. By comparing with the ref- erence simulation and scaling the results to $100 \%$ the nonlinearities in aerosol impacts from transport sources can be estimated.

An additional set of model runs is performed to analyze the sensitivity of the results to the size distributions of the emitted particles. Two additional experiments for each transport sector are carried out. To have consistent emissions in the transport and non-transport related anthropogenic emission sectors, the sensitivity experiments have to be performed for both transport and other non-transport anthropogenic sectors.

The complete list of the experiments performed for this paper is provided in Table 2 . The sensitivity experiments with different assumptions on the size distributions are described in the following.

\subsection{Land transport}

Measurements of land transport aerosol emissions are usually taken at roadside. Particle measurements in the urban environment performed at larger distances to major roadways or other dominant sources can be used to characterize the properties of an urban background aerosol at larger scales. Hence, we use the parameters of the urban background particle size distributions to determine the number concentrations of particles emitted from land transport in the large-scale simulations performed here. For the reference simulation (AEROCOM_LAND) we follow the AeroCom recommendations as given in D06 (aerocom_land size distribution; Appendix B1). The two sensitivity studies YOUNG_LAND and AGED_LAND adopt the size distribution parameters measured by Birmili et al. (2009, hereafter B09) in the Berlin area, with two different aging states (young_land and aged_land size distributions, respectively; Appendix B1). To achieve a consistent representation of all kinds of anthropogenic aerosol, these size distribution parameters are applied not only to land transport, but also to other (non-transport) sectors of anthropogenic emissions (like energy production, industry, etc.). 
Table 2. Summary of the simulations performed in this work, with the corresponding assumptions for emissions and particle size distributions. Since the reference simulation (REF) considers the aerocom_land, aged2_ship and high_air size distributions (for land transport, shipping and aviation, respectively), this experiment is also referred to as AEROCOM_LAND, AGED2_SHIP or HIGH_AIR in the text when referring to the specific sector. For the details about each size distribution see Appendix B.

\begin{tabular}{|c|c|c|c|c|c|}
\hline \multirow[b]{2}{*}{ Set } & \multirow[b]{2}{*}{ Experiment name } & \multicolumn{4}{|c|}{ Size distribution } \\
\hline & & Anthrop. non-transport & Land Transport & Shipping & Aviation \\
\hline Reference & REF & aerocom_land & aerocom_land & aged2_ship & high_air \\
\hline $\begin{array}{l}100 \% \text { reduction } \\
\text { of individual } \\
\text { sectors }\end{array}$ & $\begin{array}{l}\text { NOLAND } \\
\text { NOSHIP } \\
\text { NOAIR }\end{array}$ & $\begin{array}{l}\text { aerocom_land } \\
\text { aerocom_land } \\
\text { aerocom_land }\end{array}$ & $\begin{array}{l}- \\
\text { aerocom_land } \\
\text { aerocom_land }\end{array}$ & $\begin{array}{l}\text { aged2_ship } \\
- \\
\text { aged2_ship }\end{array}$ & $\begin{array}{l}\text { high_air } \\
\text { high_air } \\
\text { - }\end{array}$ \\
\hline $\begin{array}{l}50 \% \text { reduction } \\
\text { of individual } \\
\text { sectors }\end{array}$ & $\begin{array}{l}\text { 50LAND } \\
50 \mathrm{SHIP} \\
50 \mathrm{AIR}\end{array}$ & $\begin{array}{l}\text { aerocom_land } \\
\text { aerocom_land } \\
\text { aerocom_land }\end{array}$ & $\begin{array}{l}\text { aerocom_land } \\
\text { aerocom_land } \\
\text { aerocom_land }\end{array}$ & $\begin{array}{l}\text { aged2_ship } \\
\text { aged2_ship } \\
\text { aged2_ship }\end{array}$ & $\begin{array}{l}\text { high_air } \\
\text { high_air } \\
\text { high_air }\end{array}$ \\
\hline $\begin{array}{l}\text { Size distribution } \\
\text { land transport }\end{array}$ & $\begin{array}{l}\text { YOUNG_LAND } \\
\text { YOUNG_NOLAND } \\
\text { AGED_LAND } \\
\text { AGED_NOLAND }\end{array}$ & $\begin{array}{l}\text { young_land } \\
\text { young_land } \\
\text { aged_land } \\
\text { aged_land }\end{array}$ & $\begin{array}{l}\text { young_land } \\
- \\
\text { aged_land } \\
-\end{array}$ & $\begin{array}{l}\text { aged2_ship } \\
\text { aged2_ship } \\
\text { aged2_ship } \\
\text { aged2_ship }\end{array}$ & $\begin{array}{l}\text { high_air } \\
\text { high_air } \\
\text { high_air } \\
\text { high_air }\end{array}$ \\
\hline $\begin{array}{l}\text { Size distribution } \\
\text { shipping }\end{array}$ & $\begin{array}{l}\text { AGED1_SHIP } \\
\text { AGEDALL_SHIP }\end{array}$ & $\begin{array}{l}\text { aerocom_land } \\
\text { aerocom_land }\end{array}$ & $\begin{array}{l}\text { aerocom_land } \\
\text { aerocom_land }\end{array}$ & $\begin{array}{l}\text { aged1_ship } \\
\text { agedall_ship }\end{array}$ & $\begin{array}{l}\text { high_air } \\
\text { high_air }\end{array}$ \\
\hline $\begin{array}{l}\text { Size distribution } \\
\text { aviation }\end{array}$ & $\begin{array}{l}\text { LOW_AIR } \\
\text { NUC_AIR }\end{array}$ & $\begin{array}{l}\text { aerocom_land } \\
\text { aerocom_land }\end{array}$ & $\begin{array}{l}\text { aerocom_land } \\
\text { aerocom_land }\end{array}$ & $\begin{array}{l}\text { aged2_ship } \\
\text { aged2_ship }\end{array}$ & $\begin{array}{l}\text { low_air } \\
\text { nuc_air }\end{array}$ \\
\hline
\end{tabular}

\subsection{Shipping}

The impact of emissions from international shipping on global aerosol was already explored in a previous modeling study by Righi et al. (2011), mainly focusing on RF effects. Similar assumptions as made in that study are adopted here. In particular, ship-induced particle emissions are described by taking into account measurements of the particle size distribution in an aging ship plume (Petzold et al., 2008). The two sets of parameters obtained in these measurements are used to characterize the reference (AGED2_SHIP, considering the aged2_ship size distribution; Appendix B2) and the first sensitivity experiment (AGED1_SHIP, aged1_ship size distribution; Appendix B2). The second sensitivity experiment (AGEDALL_SHIP) considers a very aged population and is based on the AeroCom parameters (agedall_ship size distribution based on D06; Appendix B2).

\subsection{Aviation}

The reference (HIGH_AIR) and the first sensitivity (LOW_AIR) experiment both consider the size parameters measured by Petzold et al. (1999, hereafter P99) in the engine exhaust of a B737-300 aircraft (high_air and low_air size distributions, respectively; Appendix B3). These two experiments differ only in the assumed value of fuel sulfur content, corresponding to an emission index of 0.8 and $0.0052 \mathrm{~g}\left(\mathrm{SO}_{2}\right) \mathrm{kg}_{\text {fuel }}^{-1}$, respectively. The second sensitivity experiment (NUC_AIR, considering nuc_air size distribution,
Appendix B3) includes an additional nucleation mode for sulfate, based on the simulation results of Kärcher et al. (2007, hereafter K07).

\section{Total aerosol concentrations}

The total concentrations (resulting from all natural and anthropogenic emissions) of $\mathrm{BC}, \mathrm{SO}_{4}, \mathrm{NO}_{3}$ and fine $(\lesssim 1 \mu \mathrm{m})$ particle numbers calculated in the reference simulation (REF) are plotted in Fig. 2. Note that these concentrations should be interpreted as large-scale mean values representative for scales of several hundred kilometers, corresponding to the sizes of the model grid boxes. Smaller-scale phenomena such as the high local concentrations occurring in urban areas cannot be resolved.

The highest surface-level concentrations of BC (top row, left) are found over the continents, with values around $1 \mu \mathrm{g} \mathrm{m}^{-3}$ over the eastern USA, Europe, southern and eastern Asia, due to large anthropogenic emissions. Another maximum is obvious over central Africa and is due to intense biomass burning (forest and savanna fires). The zonal distribution (bottom row, left) shows the largest values close to the surface, mainly in the Northern Hemisphere, although aircraft emissions leave a signature around $250 \mathrm{hPa}$ (see Sect. 5.4 for more details about aviation effects).

The surface-level distribution of $\mathrm{SO}_{4}$ (top row, right) is basically determined by anthropogenic emissions, with the largest values $\left(\sim 10 \mu \mathrm{g} \mathrm{m}^{-3}\right)$ again over eastern USA, Europe, 
BC (REF)

Multi-year average 1996-2005

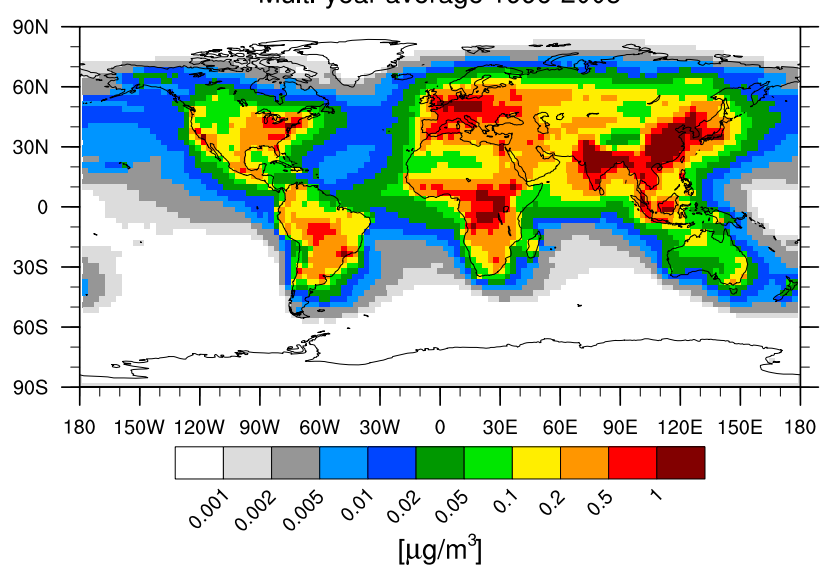

$\mathrm{NO}_{3}$ (REF)

Multi-year average 1996-2005

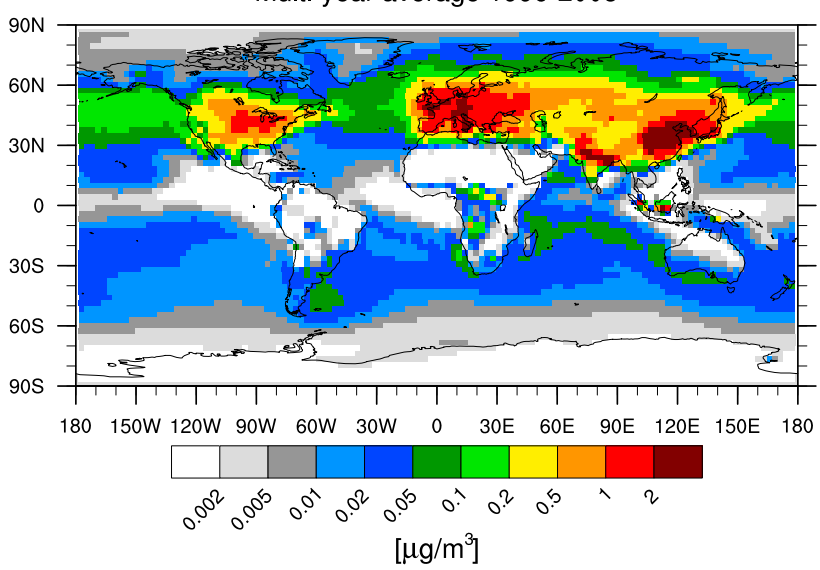

BC (REF)

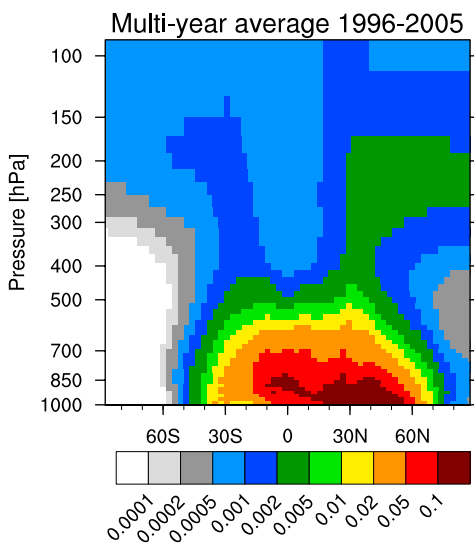

$\left[\mu \mathrm{g} / \mathrm{m}^{3}\right]$
$\mathrm{SO}_{4}$ (REF)

Multi-year average 1996-2005

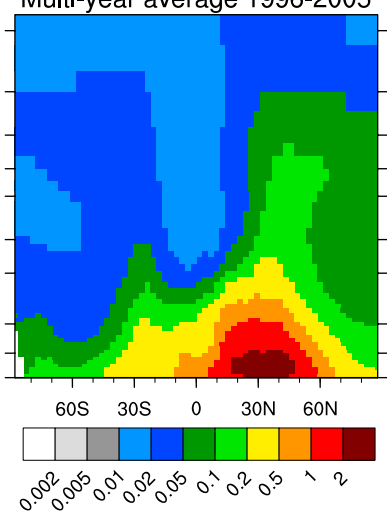

$\left[\mu \mathrm{g} / \mathrm{m}^{3}\right]$
$\mathrm{SO}_{4}$ (REF)

Multi-year average 1996-2005

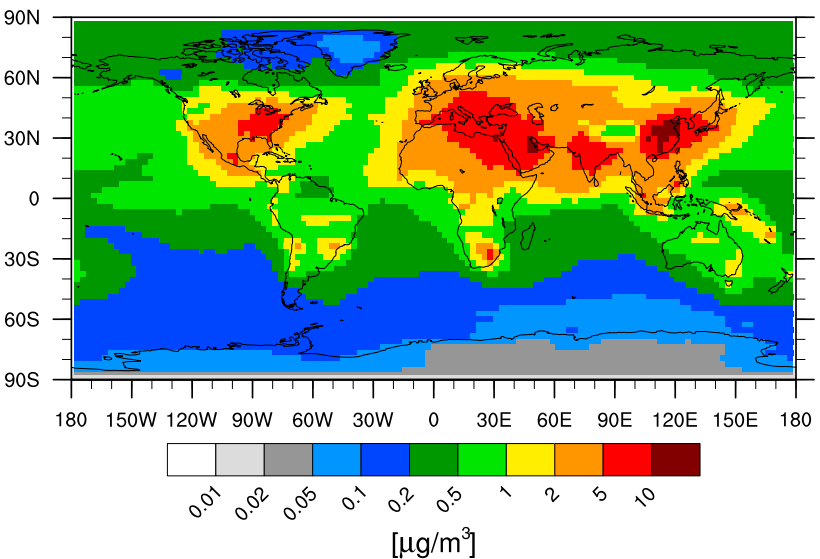

$\mathbf{N}_{\text {tot }}$ (REF)

Multi-year average 1996-2005

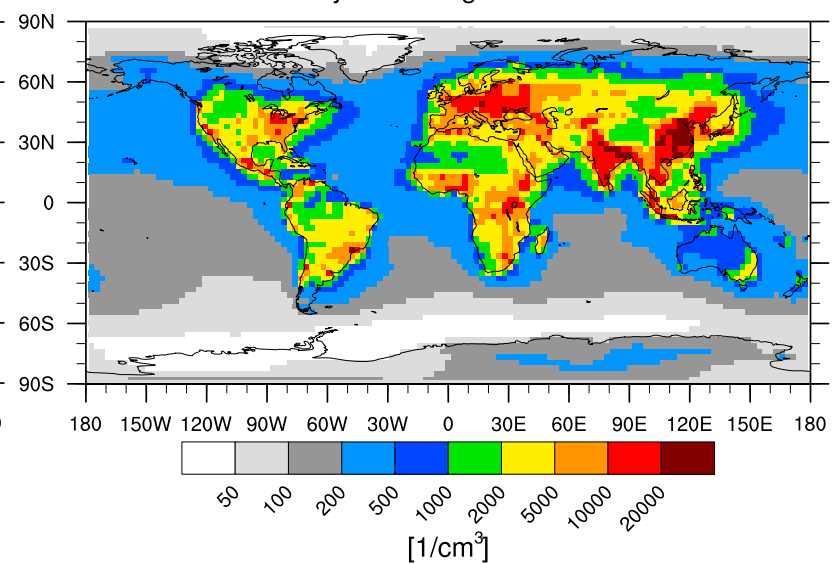

$\mathrm{NO}_{3}$ (REF)

$\mathbf{N}_{\text {tot }}$ (REF)

Multi-year average 1996-2005

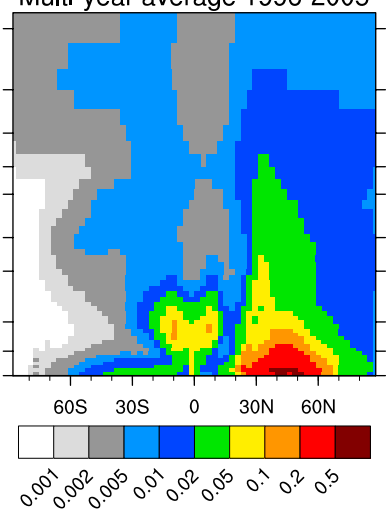

$\left[\mu \mathrm{g} / \mathrm{m}^{3}\right]$
Multi-year average 1996-2005

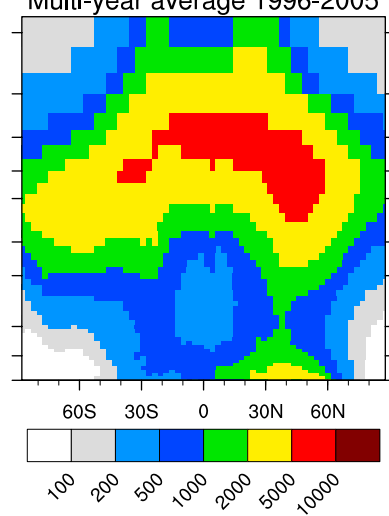

$\left[1 / \mathrm{cm}^{3}\right]$

Fig. 2. Multi-year average (1996-2005) surface-level concentrations of $\mathrm{BC}$ (top row, left), $\mathrm{SO}_{4}$ (top row, right), $\mathrm{NO}_{3}$ (middle row, left) and fine particle $(\lesssim 1 \mu \mathrm{m}$, sum of the Aitken and accumulation mode) number concentration (middle row, right) for the reference (REF) simulation. Corresponding zonal mean plots are depicted in the bottom row (the $100 \mathrm{hPa}$ level corresponds to an altitude of about $16 \mathrm{~km}$ ). 
southern and eastern Asia. A striking feature of this distribution are the relatively large concentrations $\left(\sim 1-2 \mu \mathrm{g} \mathrm{m}^{-3}\right)$ over the oceans, in particular along the continental coastlines, occurring as a consequence of ship emissions (70\% of ship emissions occur within $400 \mathrm{~km}$ of the coastlines, Corbett et al., 1999) and/or of continental plumes (Sect. 5.3).

The aerosol nitrate distribution at the surface (middle row, left) shows a clear difference between Northern and Southern hemispheres. The highest values, around $2 \mu \mathrm{g} \mathrm{m}^{-3}$, are found in correspondence of the major emission regions in North America, Europe and eastern Asia. Concentrations around $0.1 \mu \mathrm{g} \mathrm{m}^{-3}$ are simulated over the oceanic surface in the Northern Hemisphere.

The aerosol particle number concentration at the surface (middle row, right) closely matches the distribution of the mass concentrations, with maxima around $10000 \mathrm{~cm}^{-3}$ and even more. As shown in Sect. 6, these large number concentrations have to be interpreted as a maximum estimate. The zonal distribution (bottom row, right) is characterized by two maxima, a spatially confined one at the surface in the northern midlatitudes and a globally extending one in the upper troposphere. While primary particle emissions contribute a large fraction of the maximum number concentrations close to the surface, the enhanced number concentrations at upper levels are mainly a consequence of new particle formation by nucleation.

\section{Transport impacts on aerosol mass concentrations}

\subsection{General remarks}

As a starting point for the analysis, the impact of transport emissions on global atmospheric mass burdens of different aerosol components is plotted in Fig. 3, in terms of relative contributions to the total, e.g., as (REF-NOLAND)/REF for land transport. The goal is to identify the most relevant species for each sector, which will then be discussed in detail in the following sections. To this end, the burdens are computed by integrating the aerosol concentrations in those domains where emissions are likely to have their largest effects on total concentrations. This means that for land transport and shipping the integration includes only the continental and oceanic grid boxes, respectively, and is performed in the two lowermost model layers, corresponding to an altitude range of approximately $0-230 \mathrm{~m}$. For aviation, concentrations are integrated globally in model layers 7 to 9 (altitude range of about $8-13 \mathrm{~km}$ ), roughly corresponding to the cruise altitude of the commercial aircraft fleet.

$\mathrm{BC}$ and aerosol nitrate clearly dominate the aerosol burden from land transport, contributing 19.5 and $28.6 \%$ of the total mass load close to the surface, respectively. This is not surprising, given the large amount of $\mathrm{BC}$ emitted by land transport, which corresponds to $17.1 \%$ of the total (natural and anthropogenic) BC emissions in the year 2000 (Fig. 1), one

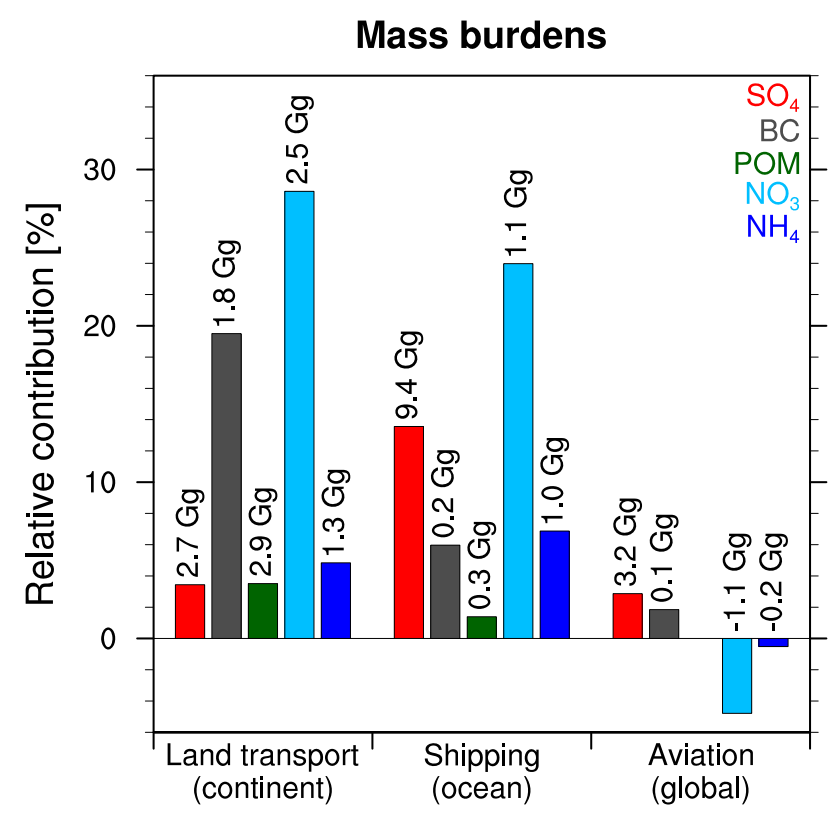

Fig. 3. Relative effects of the transport sectors on the multi-year average global atmospheric mass burdens of different aerosol components in the two lowermost model layers $(\sim 0-230 \mathrm{~m})$ for land transport and shipping (considering only mass burden over continents and oceans, respectively), and in model layers 7 to $9(\sim 8-13 \mathrm{~km})$ for aviation. The relative effects are calculated as the relative contributions (REF-NOLAND)/REF, (REF-NOSHIP)/REF and (REFNOAIR)/REF, for the three sectors, respectively, by consistently integrating the burdens over the same domains. The value on top of each bar shows the corresponding absolute contributions. The plotted values are statistically significant according to a uni-variate $t$ test (5\% error probability).

and two orders of magnitude larger than the contributions of shipping and aviation, respectively. The large contribution of $\mathrm{NO}_{3}$, on the other hand, can be explained by the high $\mathrm{NO}_{\mathrm{x}}$ emissions (28.5\% of total), but also by the low amounts of $\mathrm{SO}_{4}$ available. This means that a lower amount of ammonia is involved in the neutralization reaction to form ammonium sulfate, and therefore an excess of ammonia is available to form ammonium nitrate. The contribution of land transport to the ammonium budget is found to be on the order of a few percent.

$\mathrm{NO}_{3}$ also dominates the shipping sector burdens, with a large contribution from $\mathrm{SO}_{4}$ as well. With regard to aerosol nitrate from ship-induced $\mathrm{NO}_{\mathrm{x}}$, it should be mentioned that the uptake of nitrate in coarse mode particles is neglected in the simulations. The model considers only dust, sea salt and aerosol water in coarse particles. Due to this limitation, the simulated amount of ship-induced aerosol nitrate should be interpreted with care, since coarse sea salt particles are abundant over the ocean. BC, POM and $\mathrm{NH}_{4}$ are characterized by low contributions, although one should not forget that ships 
are the only source of anthropogenic pollution in the marine boundary layer.

Aircraft emissions cause significant increases of the $\mathrm{SO}_{4}$ and $\mathrm{BC}$ burden in the upper troposphere. In this region, the effect of aircraft induces also an interesting decrease in the $\mathrm{NO}_{3}$ burden. This is caused by the formation of additional ammonium sulfate from aviation-induced $\mathrm{SO}_{2}$, which results in less ammonium available for the formation of ammonium nitrate, a typical effect in $\mathrm{NH}_{3}$-limited environments such as the upper troposphere (Unger et al., 2013).

The geographical distributions of the transport-induced concentration changes of the individual aerosol constituents are discussed in detail in the following. Possible climate effects of the transport-induced aerosol changes are discussed in Sect. 7.

\subsection{Land transport}

The land transport effect on the BC surface-level concentration (Fig. 4, top-left panel) is mostly confined to the continents, with the largest mean values $\left(\sim 1 \mu \mathrm{g} \mathrm{m}^{-3}\right)$ over central Europe, eastern USA, southern and eastern Asia (in particular India, China, and Japan). Other major spots can be related to emissions originating from big metropolitan areas, like Los Angeles, Sao Paulo, Johannesburg, Cairo and Moscow. This pattern matches the emission pattern of land transport's BC. Significant concentrations of land-transportinduced BC can also be seen above the oceanic surface, off the coasts of the most polluted areas, with mean values around $0.05 \mu \mathrm{g} \mathrm{m}^{-3}$. These features are more obvious in relative terms (Fig. 4, bottom-left panel), with areas of about $30 \%$ relative contribution, which extend over several hundreds kilometers over the ocean, as a result of the atmospheric transport of pollutants. Another interesting feature revealed by this panel is the low relative contribution of land transport emissions to the $\mathrm{BC}$ pollution in southern and eastern Asia (10-20\%), in spite of large absolute contributions. This is due to the fact that these regions are characterized by large emissions of BC from other sectors, like energy production, industry and domestic sources, which are quite low in Europe and North America. As a result, the relative contribution of land transport is highest over Europe and North America (60-70\%), where it can be identified as the largest source of surface-level BC pollution. This result is very important in view of current and future mitigation strategies and air pollution control measures.

In a previous study, Köhler et al. (2001) performed simulations with the ECHAM4.L39(DLR) general circulation model, including a simplified description of $\mathrm{BC}$ transport and deposition, with a global inventory for BC land transport emissions for the year 1993. Their simulations indicated a similar pattern for the impact of land transport on the BC concentration at the surface, with maxima in Europe, western USA and eastern Asia. The simulated changes in concentrations, however, were lower in their case, with values generally below $1 \mu \mathrm{g} \mathrm{m}^{-3}$, in spite of a larger annual emission of $\mathrm{BC}$ (2.4 versus $\left.1.3 \mathrm{Tg} \mathrm{a}^{-1}\right)$. This discrepancy could result from the assumption of pre-defined atmospheric residence times of BC particles in the Köhler et al. (2001) study. The explicit simulation of the $\mathrm{BC}$ life cycle in the present study seems to result in distinctively longer residence times.

The land transport effect on the concentration of aerosol nitrate (Fig. 4, top-right panel) is a general increase over the most populated continental areas. Compared to BC, the distribution appears more homogeneous, revealing a more efficient atmospheric transport over the continents. Such differences in the geographical pattern result also from $\mathrm{NO}_{3}$ being a secondary aerosol component, which is formed from emitted $\mathrm{NO}_{\mathrm{x}}$ during the dispersion of the polluted air masses. The largest concentration increases $\left(>1 \mu \mathrm{g} \mathrm{m}^{-3}\right)$ are found over southern Europe and northern India. It is also interesting to note that no significant changes in the $\mathrm{NO}_{3}$ concentration are simulated for the tropical regions, probably due to the lower oxidation capacity in the tropics, which results from a less polluted background and reduces the $\mathrm{HNO}_{3}$ production rate. The pattern of relative contributions roughly follows the pattern of absolute differences, with the remarkable exception of eastern Asia, where the relative contribution is much lower for the reason given above, and South America, where it is very large. This could be due to transport sources being the dominant $\mathrm{NO}_{\mathrm{x}}$ source in the latter region.

\subsection{Shipping}

The results shown in Fig. 3 suggest that sulfate is a substantial particle pollutant from shipping. Our simulations reveal that the long-term and large-scale mean surface-level concentration of $\mathrm{SO}_{4}$ related to shipping can be higher than $1 \mu \mathrm{g} \mathrm{m}^{-3}$ near the European coastlines, especially in the Mediterranean, on the East Asian coastlines and off the western USA (Fig. 5, left panel). High average concentrations, in the range $0.2-1 \mu \mathrm{g} \mathrm{m}^{-3}$, are found nearly everywhere over the oceans in the Northern Hemisphere. In the Southern Hemisphere, the impacts are generally lower, with the exception of some major shipping routes off the coast of Africa, South America and Australia. The impact of shipping-induced sulfate is significant not only above the ocean surface, but also over parts of the continents. Important ship-induced concentration increases are simulated for western Europe and northern Africa, and for the coastal areas of North America and eastern Asia. This can have detrimental effects on the air quality, and consequently on human health, in these regions (Corbett et al., 2007; Winebrake et al., 2009). In relative terms, the largest ship-induced contributions to aerosol sulfate are simulated for the northern Pacific Ocean in the latitude range $30-60^{\circ} \mathrm{N}$, with values larger than $50 \%$, and along the major routes of the northern Atlantic.

In a similar study with a previous version of the model, Lauer et al. (2007) reported comparable estimates for the impact of international shipping on $\mathrm{SO}_{4}$, considering different 

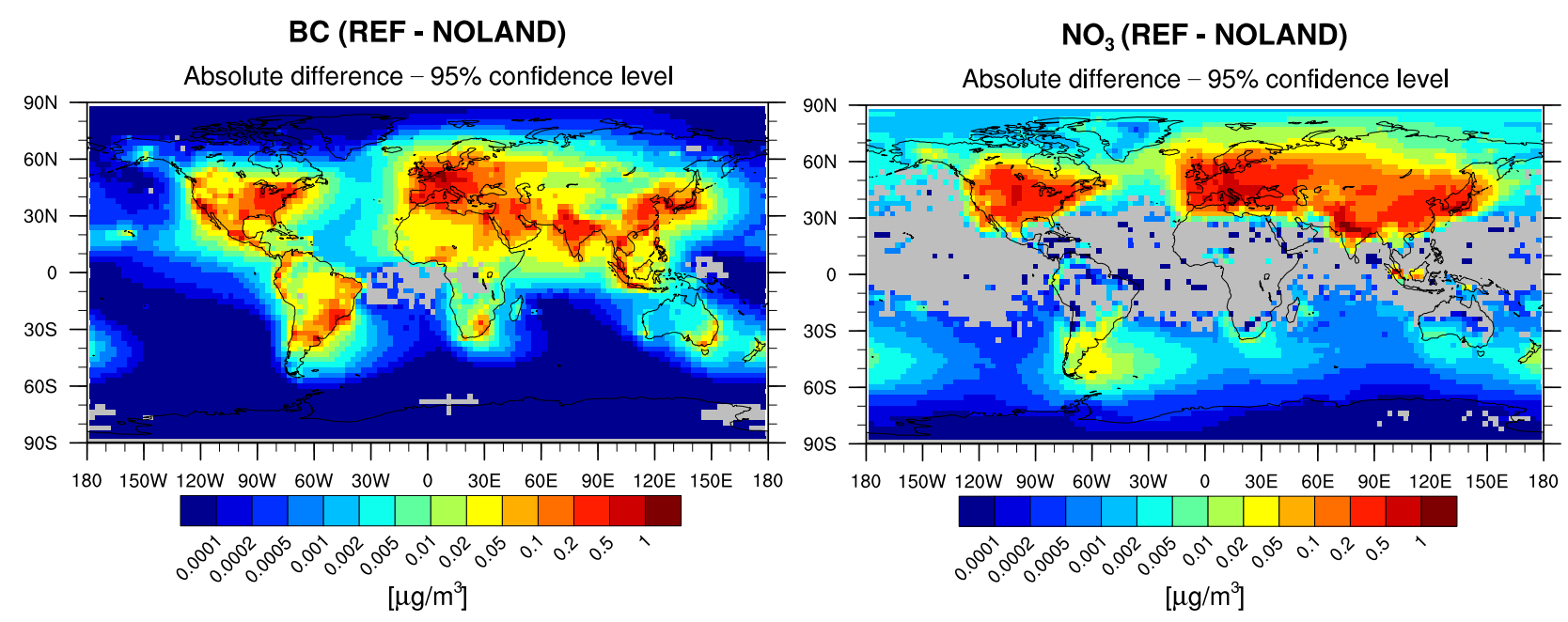

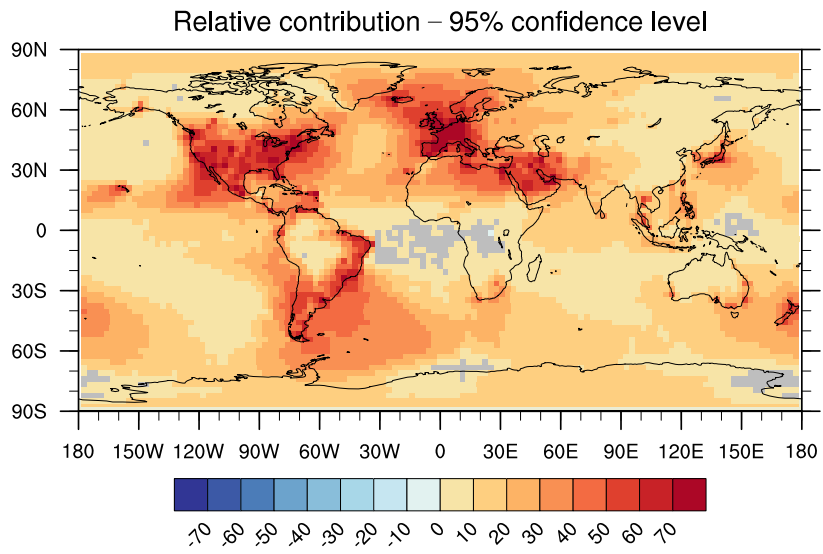

[\%]

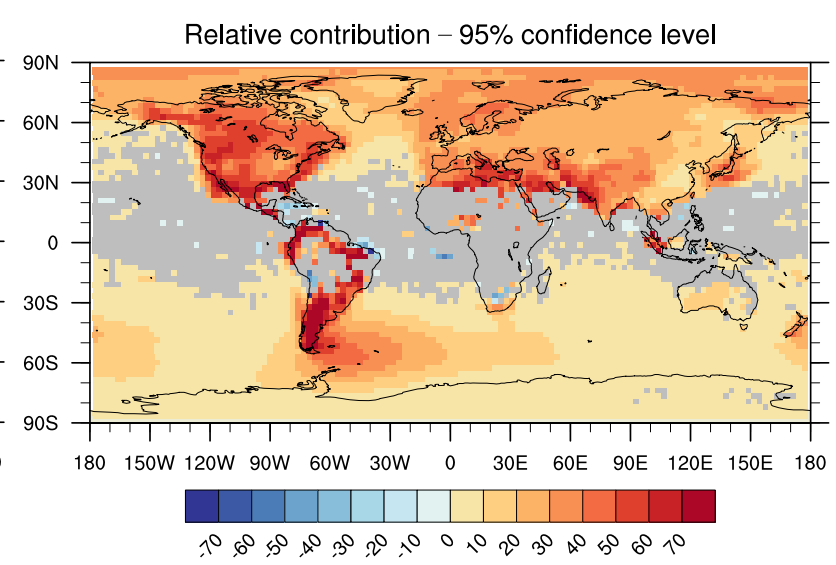

[\%]

Fig. 4. Multi-year average (1996-2005) of the absolute (top) and the relative effect (bottom) of land transport on BC (left) and aerosol nitrate $\left(\mathrm{NO}_{3}\right.$, right) concentrations at the surface. Plotted are the differences between the experiments REF and NOLAND. The relative effect is calculated as the relative contribution (REF-NOLAND)/REF. Grid points where the difference is not statistically significant according to a uni-variate $t$ test ( $5 \%$ error probability) are masked out in gray.

emission inventories. In particular their results for Inventory C, based on Wang et al. (2007), are very similar to the ones presented here. This was expected, given that Inventory $\mathrm{C}$ and the inventory used here (Lamarque et al., 2010) are both based on the same geographical distribution of ship emissions (ICOADS), although Inventory $\mathrm{C}$ has $15 \%$ lower $\mathrm{SO}_{2}$ emissions ( 9.2 versus $\left.10.8 \mathrm{Tg} \mathrm{a}^{-1}\right)$.

Our present estimates are obtained considering year 2000 emissions. It can be expected that emissions from shipping will change in the near future, due to recent regulations introduced on shipping fuel sulfur content by the International Maritime Organization (IMO; Buhaug et al., 2009). According to such measures, the sulfur content is going to be reduced from the current (2010) global average value of $2.7 \%$ (by mass) to $0.5 \%$ by 2020 , and to $0.1 \%$ by 2015 in the so-called Sulfur Emissions Control Areas (SECAs, e.g., the North Sea and the Baltic Sea). This will lead to $40-60 \%$ re- ductions in ship-induced, surface-level sulfur concentrations along the most traveled routes (Righi et al., 2011).

The shipping effect on $\mathrm{NO}_{3}$ surface-level concentration (Fig. 5, right panel) is largest in the northern Pacific and around Europe, but also affects the European continental areas, with mean values in the range $0.1-0.5 \mu \mathrm{g} \mathrm{m}^{-3}$. In spite of relatively low absolute values, the relative contributions (lower panel) are very large and above $50 \%$ over most of the oceanic surface in the Northern Hemisphere and along the most traveled routes of the Southern Hemisphere, which results from the comparatively clean marine background.

\subsection{Aviation}

Figure 6 presents vertical distributions of zonal mean aviation-induced changes in the concentrations of $\mathrm{BC}, \mathrm{SO}_{4}$ and $\mathrm{NO}_{3}$. For the first two species, the impact is highest in the northern extratropical tropopause region, at around $250 \mathrm{hPa}$ 

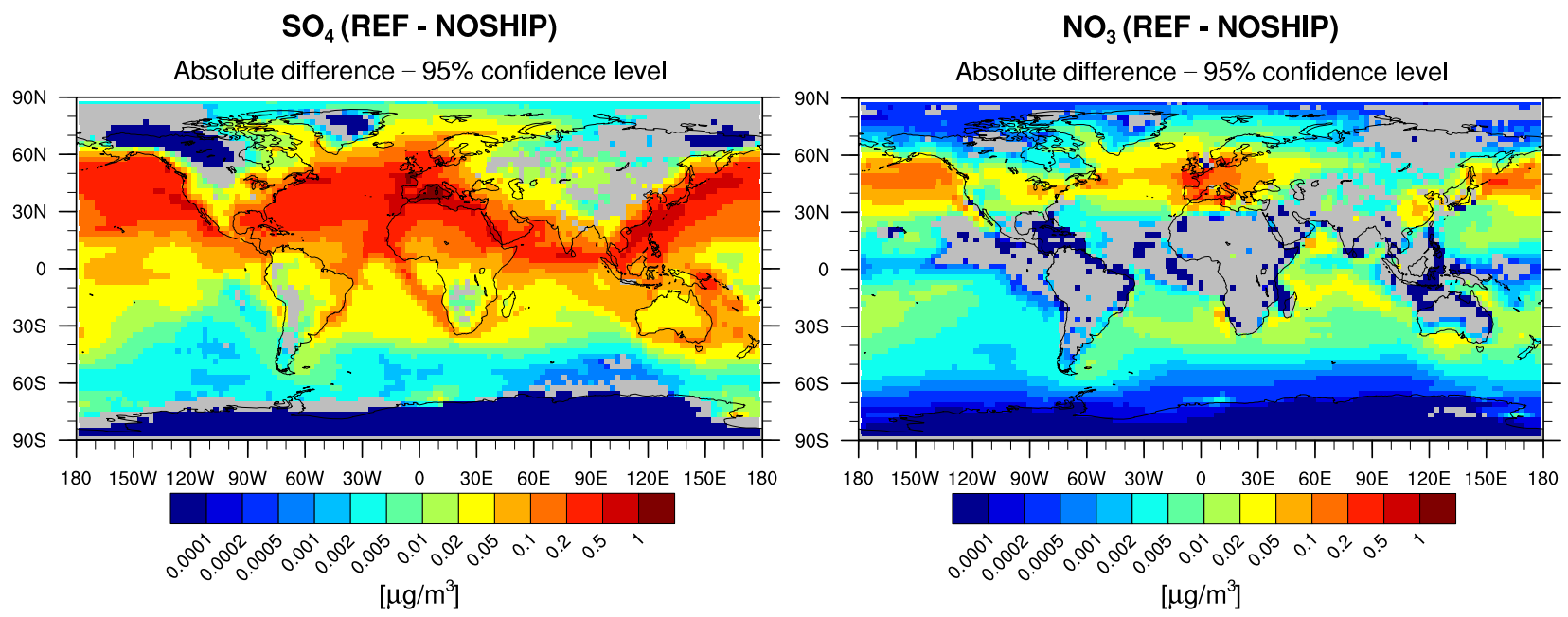

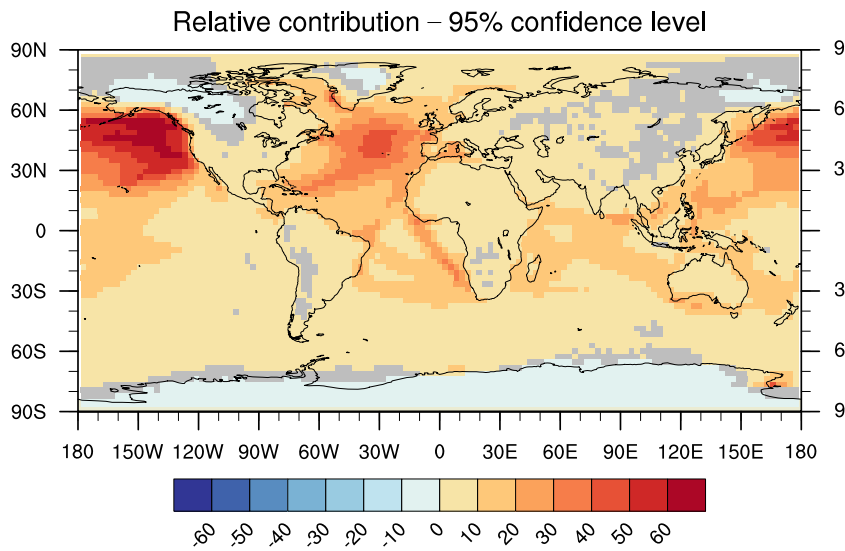

$[\%]$

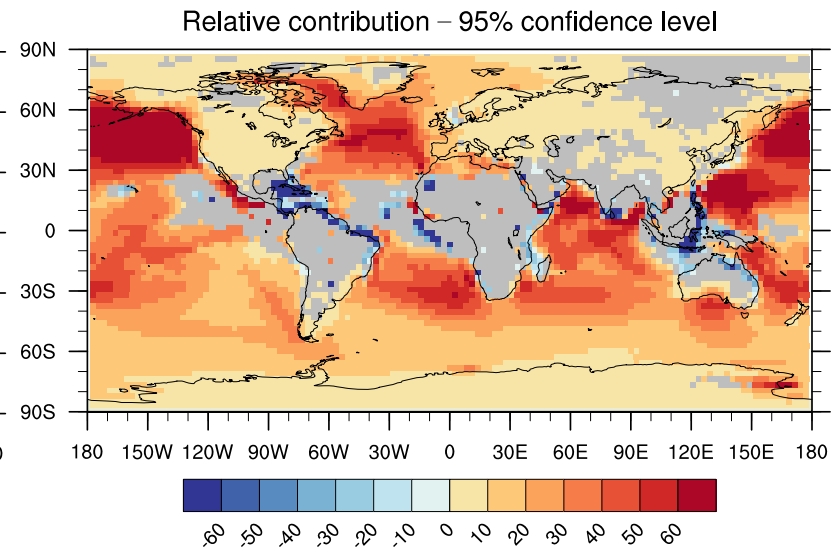

$[\%]$

Fig. 5. Multi-year average (1996-2005) of the absolute (top) and the relative effect (bottom) of shipping on $\mathrm{SO}_{4}$ (left) and aerosol nitrate $\left(\mathrm{NO}_{3}\right.$, right) concentrations at the surface. Plotted are the differences between the experiments REF and NOSHIP. The relative effect is calculated as the relative contribution (REF-NOSHIP)/REF. Grid points where the difference is not statistically significant according to a uni-variate $t$ test ( $5 \%$ error probability) are masked out in gray.

$(\sim 10 \mathrm{~km})$, i.e., at the typical cruise altitudes of commercial aircraft. Another striking feature can be identified close to the surface, below $800 \mathrm{hPa}$, around $30^{\circ} \mathrm{N}$. This is likely due to aircraft emissions released during landing, take-off and taxiing activity at airports. The impact on $\mathrm{BC}$ is essentially limited to these two regions, whereas the $\mathrm{SO}_{4}$ signature is also visible in the Southern Hemisphere at higher altitudes ( $250 \mathrm{hPa}$ and above). In absolute terms, the highest impact of BC from aircraft amounts to $0.05-0.1 \mathrm{ng} \mathrm{m}^{-3}$ at cruise altitude and up to $0.5 \mathrm{ng} \mathrm{m}^{-3}$ near the surface. The impact of $\mathrm{SO}_{4}$ is much higher, reaching levels above $10 \mathrm{ng} \mathrm{m}^{-3}$ near the surface and of $2-5 \mathrm{ng} \mathrm{m}^{-3}$ at cruise altitude. In relative terms, the impact of aviation is relevant only at cruise altitude, with values around 3 to $5 \%$, while close to the surface other sources dominate.

The aviation-induced $\mathrm{NO}_{3}$ perturbation shows a completely different pattern. In the northern midlatitudes the effect of aviation emissions is a net decrease of about $1 \mathrm{ng} \mathrm{m}^{-3}$ (more than $20 \%$ in relative terms). The reason for this decrease is the relatively high amount of sulfate generated by aircraft emissions at these altitudes. As discussed in Sect. 5.1, this results in an increasing amount of ammonium sulfate at the expense of ammonium nitrate. At lower altitudes and close to the surface where more ammonium is available, the effect of aviation is an increase in aerosol nitrate concentration of about $5-10 \mathrm{ng} \mathrm{m}^{-3}$.

In a previous model study with ECHAM4, Hendricks et al. (2004) reported an aviation BC impact of $0.02-0.05 \mathrm{ng} \mathrm{m}^{-3}$, slightly lower than our present value, in spite of comparable total $\mathrm{BC}$ emissions from this sector $\left(\sim 0.005 \mathrm{Tg} \mathrm{a}^{-1}\right)$. Relative impacts of aviation on $\mathrm{BC}$ were also reported to be below $10 \%$ by Liu et al. (2009) using the NCAR CAM3 general circulation model coupled to the IMPACT global aerosol model.

Unger (2011) used the NASA GISS ModelE to calculate the aviation impacts on sulfate and nitrate for standard and 

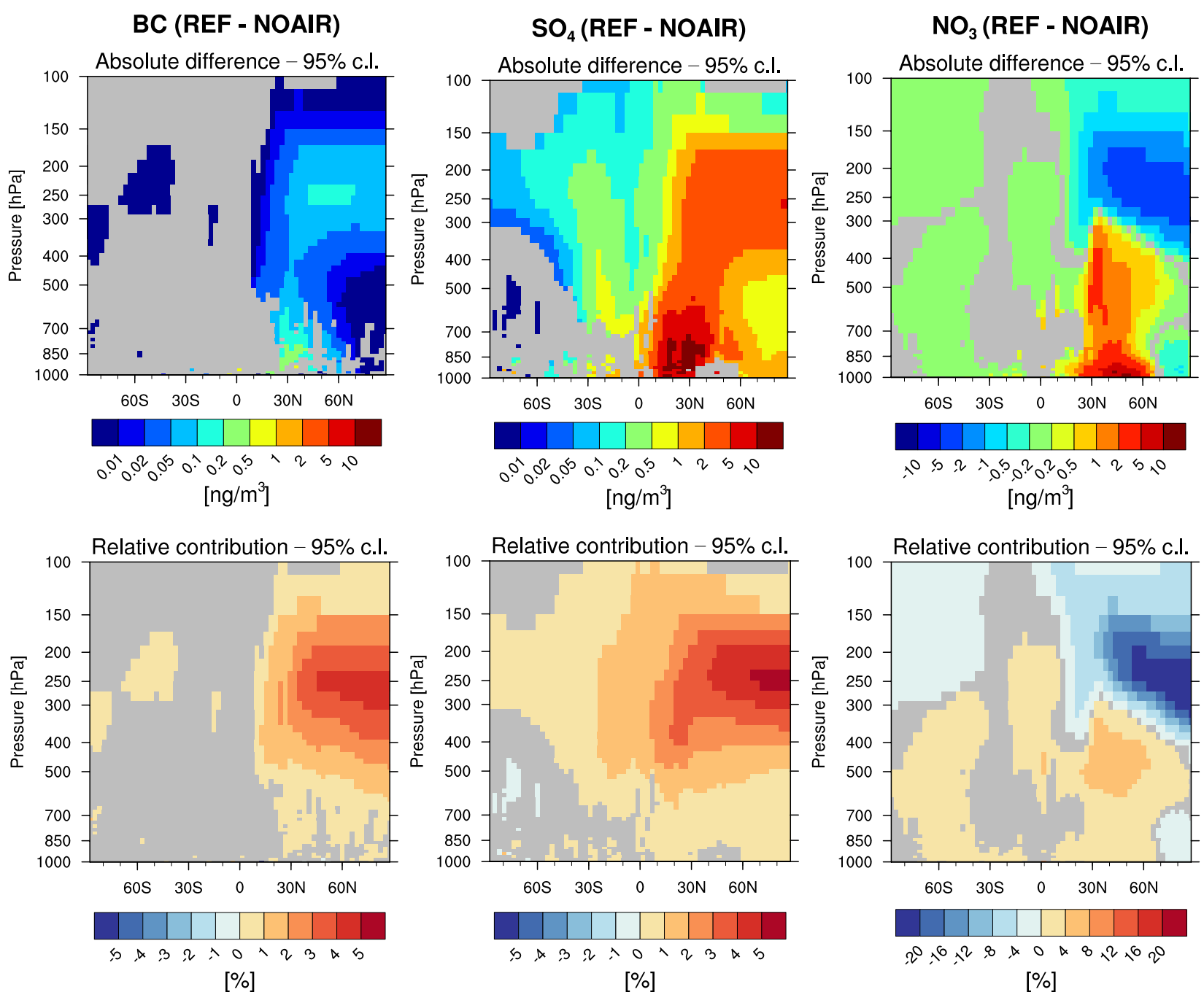

[\%]

Fig. 6. Multi-year average (1996-2005) zonal means of the absolute (top) and the relative effect (bottom) of aviation on $\mathrm{BC}$ (left), $\mathrm{SO}_{4}$ (middle) and aerosol nitrate $\left(\mathrm{NO}_{3}\right.$, right) concentrations. Plotted are the differences between the experiments REF and NOAIR. The relative effect is calculated as the relative contribution (REF-NOAIR)/REF. Grid points where the difference is not statistically significant according to a uni-variate $t$ test ( $5 \%$ error probability) are masked out in gray.

desulfurized fuels. The resulting patterns closely match those presented in Fig. 6 for the same species, although the relative impacts of aviation-induced sulfur calculated by Unger (2011) are significantly higher for both the standard and the desulfurized fuel case. This is probably due to the higher sulfur content assumed in that study for both fuel types (1.2 versus 0.8 and 0.03 versus $0.0052 \mathrm{~g}\left(\mathrm{SO}_{2}\right) \mathrm{kg}_{\text {fuel }}^{-1}$, for standard and the desulfurized fuel, respectively). A better agreement between Unger (2011) and our results is found for $\mathrm{NO}_{3}$.

\section{Transport impacts on aerosol number concentrations and size distribution}

\subsection{General remarks}

The impact of a given source on aerosol number concentrations is strongly dependent on the size distribution of particles emitted by that source. The assumptions about the parameters describing the size distributions of emitted particles in model simulations are a significant source of uncertainty. This is due to the relatively limited number of available observational data that constrains the parameters, as well as to intrinsic difficulties in their determination. Size distributions of aerosol induced by emissions from the transport sectors can be influenced by the ambient conditions, which can be highly variable in the global domain. Moreover, global 


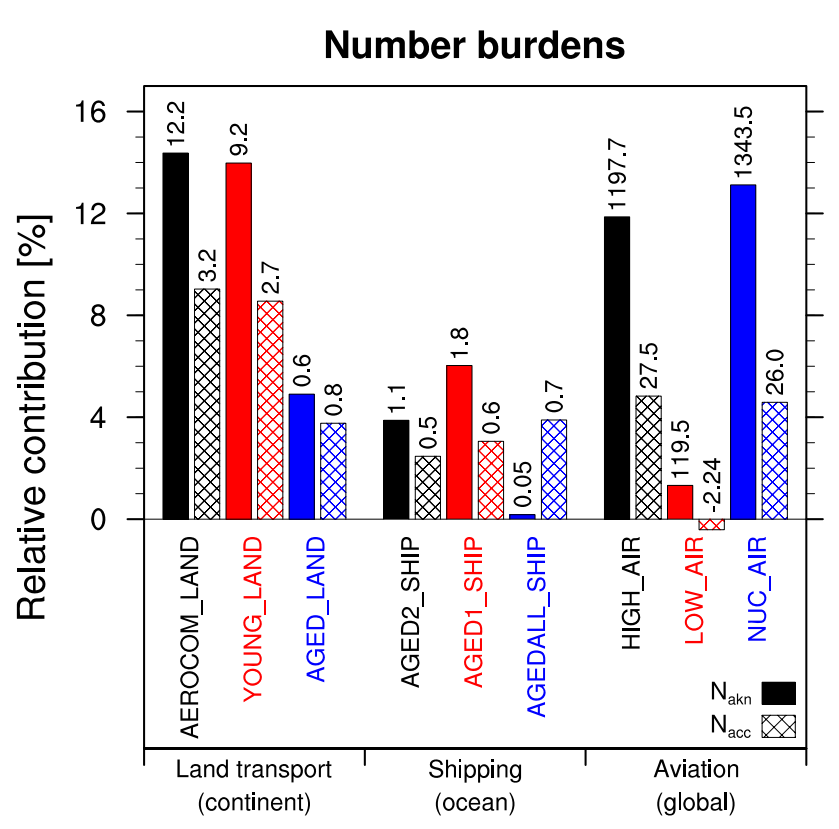

Fig. 7. Relative effects of the transport sectors on the multi-year average number burdens of particles in the Aitken (solid pattern) and accumulation (hatched pattern) mode size ranges as obtained for the different sensitivity analyses. The names of the sensitivity experiment are written at the bottom of the corresponding bars. Similarly to Fig. 3, land transport and shipping contributions are integrated over continents and oceans, respectively, and over the two lowermost model layers $(\sim 0-230 \mathrm{~m})$. Model layers from 7 to $9(\sim 8-$ $13 \mathrm{~km}$ ) are considered for aviation. The relative effect is calculated as a relative contribution, consistently integrating the burdens over the same domains. The number on top of each bar shows the corresponding absolute contributions (in units of $10^{24}$ particles). The plotted values are statistically significant according to a uni-variate $t$ test (5\% error probability).

models cannot resolve the typical spatial scales of the emission sources, and the processes occurring during the evolution of exhaust on subgrid scales must remain hidden. As discussed in Sect. 2.2, in the present work we aim at quantifying the related uncertainties by means of a set of sensitivity experiments with different size distributions representative for different aging states of the emitted particles. The results are discussed in this section.

In analogy to the discussion of mass concentrations (Sect. 5), we use the tropospheric aerosol (number) burdens as a starting point. The relative contributions of the transport sectors to the number burden in the Aitken and accumulation modes as simulated by the model are shown in Fig. 7, for each individual sector and the corresponding sensitivity experiments. As for the mass burdens presented in Fig. 3, the contributions of land transport and shipping are integrated over the continents and over the oceans, respectively, considering the two lowermost model layers $(\sim 0-230 \mathrm{~m})$. The aviation contribution is integrated globally in the $8-13 \mathrm{~km}$ altitude range.

Applying the land transport aerosol size distribution used as reference (aerocom_land, from D06) provides similar results as the application of the young_land distribution based on the observations of B09. The two respective experiments (AEROCOM_LAND and YOUNG_LAND) result in similar contributions to the total aerosol number burden close to the surface (about 14 and $9 \%$ for the Aitken and accumulation modes, respectively). This is an important result, that supports the AeroCom recommendations with the size distribution parameters gained from observations in the urban environment. The other sensitivity run for land transport (AGED_LAND) assumes a more aged aerosol population in the emission calculations and results in a lower relative contribution to the modeled number burden, a factor of 2-3 less than the first two cases. Another interesting difference is the relative importance of the Aitken and accumulation mode. In the AEROCOM_LAND and YOUNG_LAND experiments, land-transport-related particles have a distinctively larger contribution to the number burden of particles in the Aitken mode size range than to the burden of particles in accumulation mode. In the AGED_LAND experiment, the two contributions are similar.

For ship-induced particles, two different size distributions observed in aged ship-plumes (aged2_ship and aged1_ship) as well as a very aged size distribution (agedall_ship) are considered to estimate particle number emissions. In analogy to the results by Righi et al. (2011), the AGED2_SHIP and AGED1_SHIP experiments show similar results. The largest differences occur in the Aitken mode where the AGED1_SHIP case shows a slightly larger ship-induced particle number contribution. The extreme AGEDALL_SHIP case, with no emission in the Aitken mode, results in a similar accumulation mode particle number contribution as in the AGED1_SHIP and AGED2_SHIP experiments. However, there is nearly no effect on the Aitken mode, since only emissions of larger particles are considered. The small contribution simulated for the Aitken mode size range is due to the nucleation of new particles induced by the formation of gaseous sulfate from ship-induced $\mathrm{SO}_{2}$.

For the aviation sector, the LOW_AIR and the NUC_AIR experiments are intended to represent two extreme cases, respectively accounting for a minimum and maximum estimate of the number of particles emitted by aircraft (see Appendix B3). Compared to HIGH_AIR, the NUC_AIR case shows indeed a larger aviation-induced particle contribution to the Aitken mode, but the difference is small, while for the accumulation mode the two values are almost identical. A much lower burden is obtained for the LOW_AIR case, as expected, revealing the high importance of fuel sulfur content in determining the number budget in the upper troposphere. Such a strong reduction is very relevant in view of future prospects for low-sulfur fuels in aviation and is discussed in more detail in the following sections. 
The results presented in Fig. 7 indicate that a range of possible contributions to the total particle number burden can be found for each sector. We will interpret these ranges in terms of uncertainties inherent in the simulations of the effects of transport emissions on the large-scale aerosol particle number burdens. The reasons for these uncertainties are subgrid-scale transformations and, in the specific case of aviation, variations in aircraft fuel sulfur content. The quantified uncertainties will be considered to derive uncertainty ranges of the climate effects of transport-induced aerosol in Sect. 7. In the following, we analyze the spatial distributions of the number perturbations with a particular focus on those cases that span the range of uncertainties discussed above.

\subsection{Land transport}

The impact of land transport on the global surface-level distribution of the aerosol number concentration of fine particles (Aitken and accumulation modes, with diameter less than about $1 \mu \mathrm{m}$ ) as obtained in the reference simulation (AEROCOM_LAND) is presented in the left panel in Fig. 8. The pattern closely matches the BC impacts (Fig. 4, left panel): The largest changes are found over the eastern USA, eastern South America, western Europe, the Arabian Peninsula and southern and eastern Asia, where the land transport contribution to number concentrations is about $2000-5000 \mathrm{~cm}^{-3}$. This corresponds to a relative contribution of about $30-50 \%$, with the exception of southern and eastern Asia, where the presence of other sources of pollution results in a less pronounced relative impact of land transport, as already discussed in the previous section.

The land transport effect is very sensitive to the assumptions on the size distribution of particles emitted by this source. The experiment considering a very aged particle size distribution (AGED_LAND), where very fine anthropogenic particles (NUC mode in Table 1) are assumed to be removed by uptake in larger particles, reveals a much smaller impact on the large-scale number concentrations (Fig. 8, right panel). Although the geographical distribution appears very similar, changes in number concentration are about one order of magnitude lower than in the reference case, around 200 $500 \mathrm{~cm}^{-3}$, with a relative contribution of about $20-30 \%$ in the most affected regions.

The loss of very fine emitted particles, due to coagulation with larger particles, cannot be fully represented in the largescale models since urban plumes with high concentrations of aerosol are not resolved. Due to the dependence of the loss efficiency on the number concentration of the larger particles, the loss is probably underestimated and the number concentration of very fine particles might be too high in the reference simulation. In the AGED_LAND experiment, we assume that the emitted very fine particles are completely taken up by the larger ones on subgrid scales. Hence the large-scale number concentration of fine particles is probably underestimated. We conclude from this analysis that the two model simulations AEROCOM_LAND and AGED_LAND span the range of uncertainty resulting from the coarse spatial resolution of the global model. A best estimate of the particle number perturbation is currently not possible, since an appropriate parameterization of subgrid-scale plume processes is not yet available. An option for future work could be the development of such a parametrization, by deriving fine particles loss rates from plume model simulations or from highresolution regional model experiments. The identification of a best estimate by evaluation of the modeled particle number concentrations with measurements is also critical. The available station data usually represents specific local conditions, which limits the comparability of the measured concentrations with the large-scale concentrations simulated in global climate models (Aquila et al., 2011).

The effect of land transport emissions on the particle size distribution is shown in the left panel in Fig. 9, for the continental regions, in the two lowermost model layers. The AEROCOM_LAND and YOUNG_LAND experiments show similar results (confirming the findings discussed in Sect. 6.1). The largest impact of land transport emissions on number concentrations occurs in the size range $30-50 \mathrm{~nm}$, typical for the Aitken mode. The effect is shifted towards higher diameters, about $80-100 \mathrm{~nm}$, when the aged_land distribution is used for the emitted particles and is characterized by a much smaller amplitude. We can draw the general conclusion that land transport has the potential to cause distinctive increases in the large-scale concentration of particles, particularly in the size range from about 10 to $200 \mathrm{~nm}$.

\subsection{Shipping}

In the case of shipping, the sensitivity of particle number concentration effects to the adopted size distribution is smaller than for land transport. In Figure 10, the impact on number concentration for the AGED2_SHIP and AGEDALL_SHIP experiments is shown. The largest changes along the most traveled routes are around 200 and $100 \mathrm{~cm}^{-3}$ in the two experiments, respectively.

As shown in Fig. 7, the Aitken mode is more sensitive to the choice of the size distribution than the accumulation mode. When comparing the AGED2_SHIP to the AGEDALL_SHIP experiment, a compensation effect is evident, since the large decrease in Aitken mode particle number concentration is partly compensated by an increase in the number of accumulation mode particles. This partly explains the relatively low impact of the adopted size distribution on the total number concentration of fine particles. If the individual size modes are considered, the impact can be much larger. An additional reason is that ultra-fine particles are efficiently taken up by larger aerosol particles in ship plumes and thus are almost completely missing in the aged ship emission plumes considered here (Petzold et al., 2008). Therefore the large uncertainties resulting from the fate of these particles are not relevant for the shipping sector. 


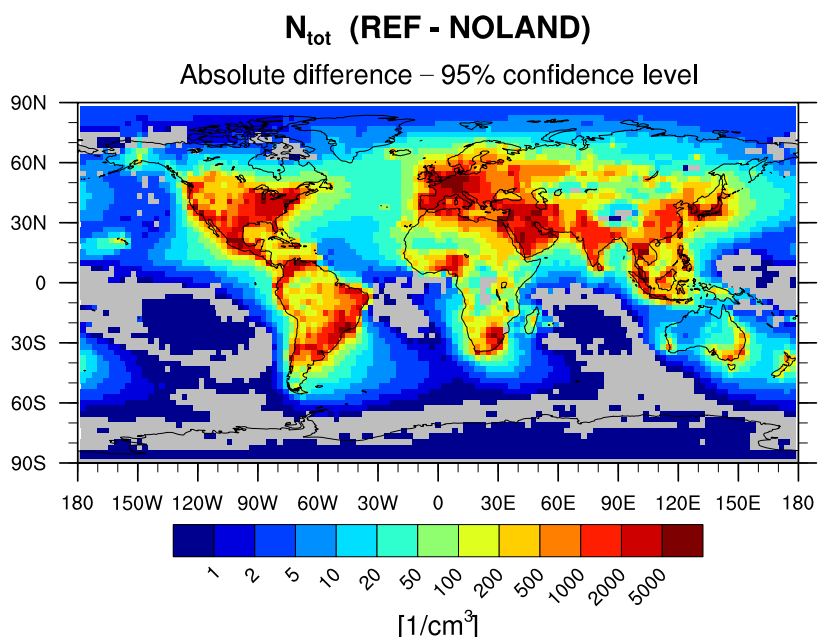

$\left[1 / \mathrm{cm}^{3}\right]$
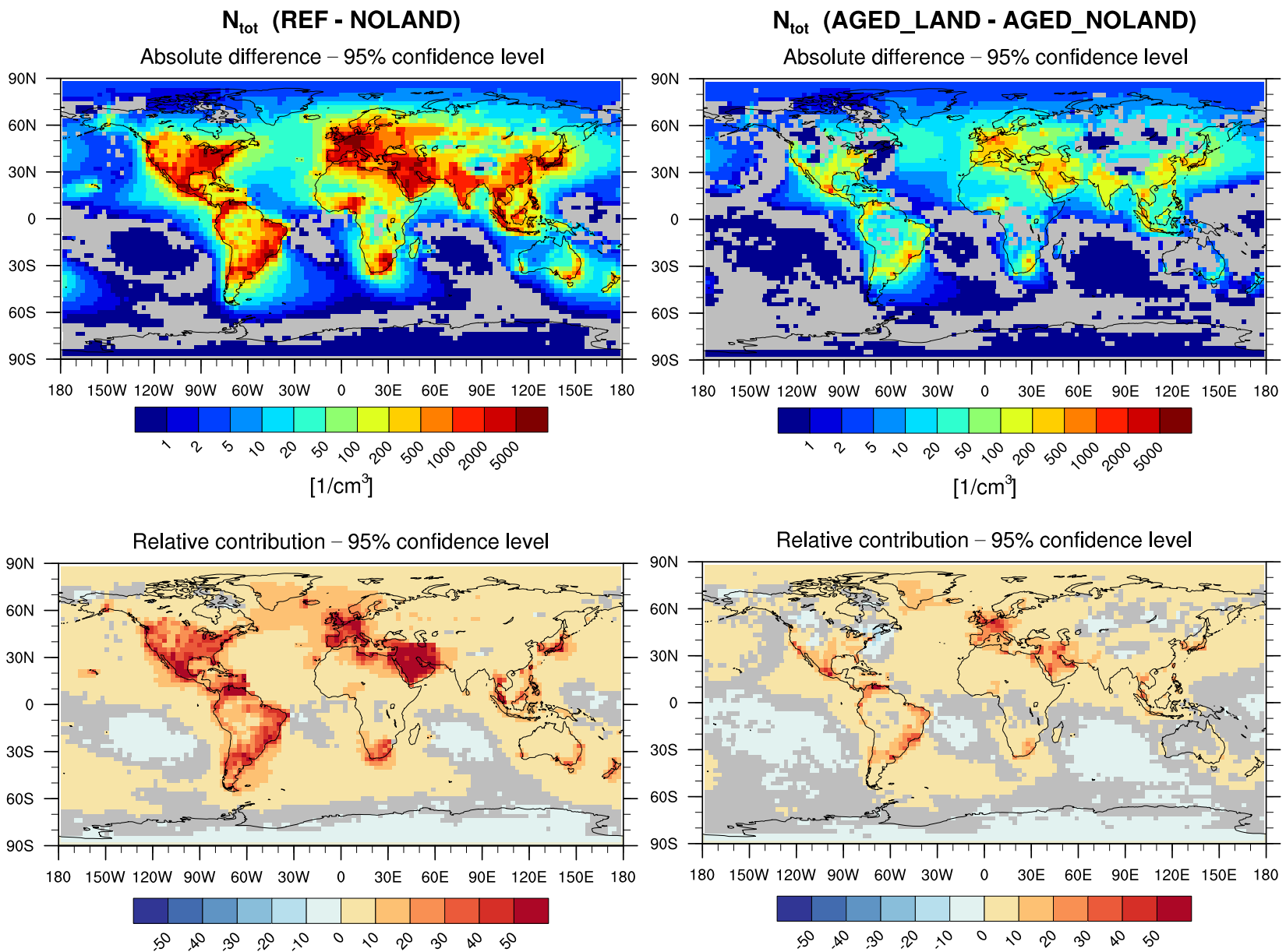

[\%]
Relative contribution - 95\% confidence level

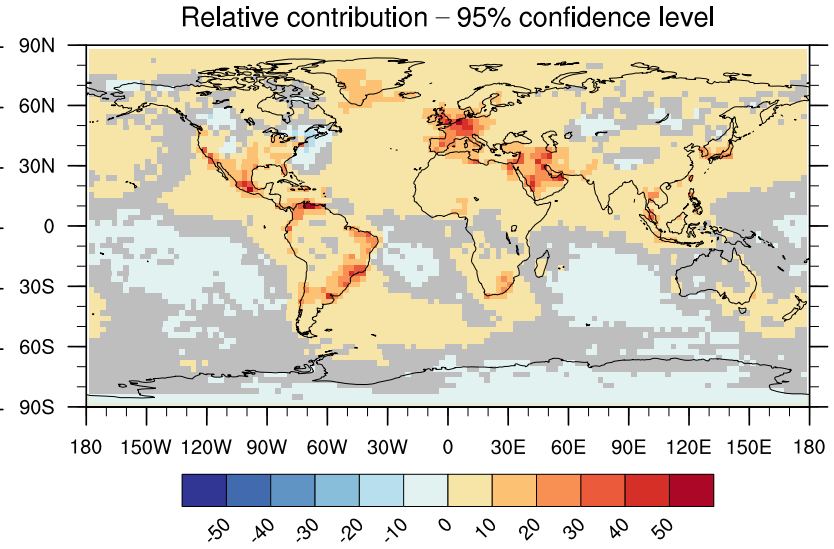

[\%]

Fig. 8. Multi-year average (1996-2005) of the absolute (top) and the relative effect (bottom) of land transport on the Aitken and accumulation mode particle number concentration at the surface. Plotted are the differences between the experiments AEROCOM_LAND (REF) and NOLAND (left) and between AGED_LAND and AGED_NOLAND (right). The relative effect is calculated as the relative contribution (REF-NOLAND)/REF (left) and (AGED_LAND-AGED_NOLAND)/AGED_LAND (right). Grid points where the difference is not statistically significant according to a uni-variate $t$ test (5\% error probability) are masked out in gray.

An analysis of the changes in the median particle size distribution (Fig. 9, middle panel) reveals that shipping emissions result in a significant decrease in the concentration of particles with sizes in the range of 5-20 nm and a comparatively large concentration increase in the $20-200 \mathrm{~nm}$ size range. This result supports the findings of Lauer et al. (2007) that global ship emissions result in an increase in the concentration of aerosol particles serving as cloud condensation nuclei. The simulation AGEDALL_SHIP, which does not include emissions in the Aitken mode, results in a similar size distribution change, but with lower amplitude for both size modes.

\subsection{Aviation}

The modeled changes in number concentrations induced by aircraft emissions are mainly confined to the northern midlat- itudes, at cruise altitude (Fig. 11). This was expected, since changes in mass concentration are also largest in this region. The mean increase in particle number concentration in this area amounts to about $1000-2000 \mathrm{~cm}^{-3}$ in the two experiments with high fuel sulfur content (HIGH_AIR and NUC_AIR), with a relative impact of about $30-40 \%$. The differences between the HIGH_AIR and NUC_AIR experiments are quite small, revealing that the consideration of aircraft-generated particles in the nucleation mode size range does not induce significant changes in the average number concentrations. The reasons for this effect can be twofold. On the one hand, gaseous sulfate produced from aircraft exhaust can nucleate new very fine particles in the HIGH_AIR experiment, while in NUC_AIR the sulfate might predominantly condense on the abundant preexisting fine particles. This might result in similar concentrations of very fine particles in the two experiments. On the other hand, the nucleation 

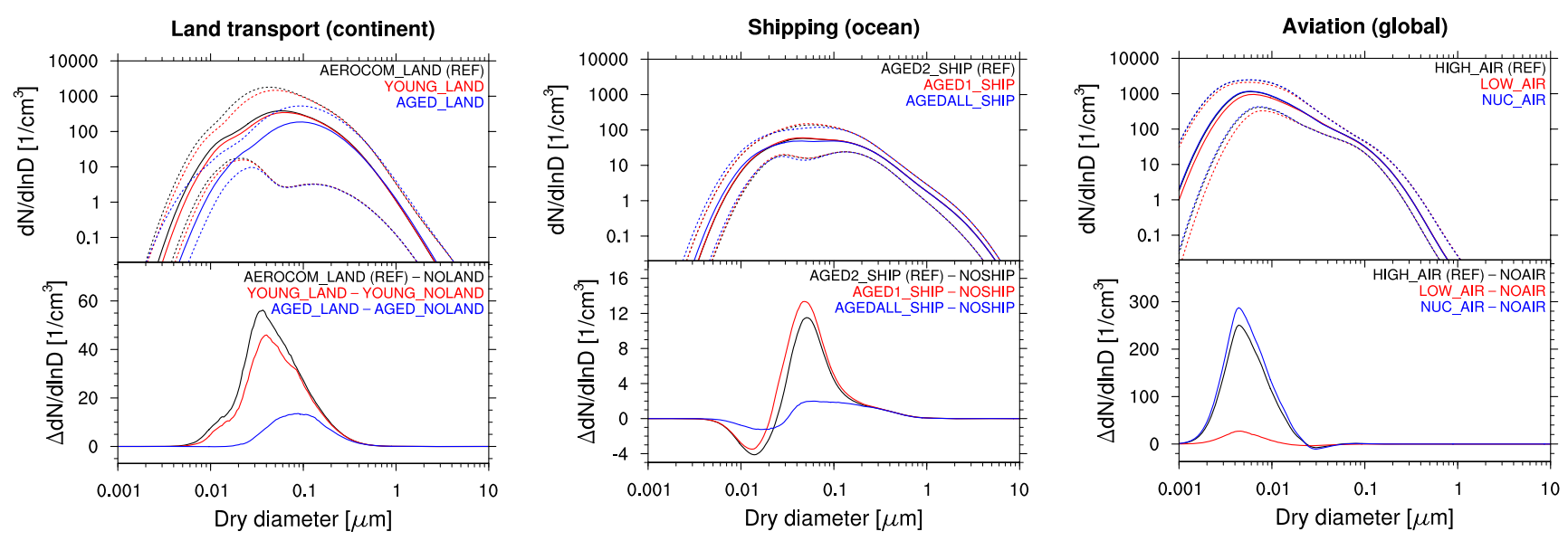

Fig. 9. Aerosol median size distributions for land transport (left), shipping (middle) and aviation (right). In the case of land transport (shipping), the size distributions are calculated considering the continental (oceanic) grid boxes only, and the two lowermost model layers. Aviation impacts are calculated on the global domain, in model layers 7 to $9(\sim 8-13 \mathrm{~km})$. The top panels show the median distributions (solid lines) as well as the 25 and $75 \%$ quartiles (dotted lines). The bottom panels show the differences in the median size distributions between experiments with and without the given transport source. Median and quartiles are calculated by considering 200 logarithmic size bins in the $10^{-3}-10 \mu \mathrm{m}$ range and analyzing number concentrations in each bin.

mode particles emitted in the NUC_AIR simulation are subject to coagulation. Although less efficient in the upper troposphere than at the ground, this process might lead to a significant reduction of the number concentration of the very fine emitted particles in the NUC_AIR experiment, forcing the total concentration towards that obtained in the HIGH_AIR simulation. A slightly higher impact on the number concentration, however, can be identified for the NUC_AIR experiment, especially in the levels below $400 \mathrm{hPa}$.

The low-sulfur experiment LOW_AIR shows a significantly lower impact on number concentration, roughly 200$500 \mathrm{~cm}^{-3}$, and only a few percent in relative terms. This reveals that the uncertainties of the aviation effect on total aerosol particle number concentrations are largely due to assumptions on the fuel sulfur content.

Again, these findings are supported by the size-resolved median number concentrations shown in Fig. 9 (right panel). The two high-sulfur experiments show nearly identical aircraft effects on the aerosol size distribution, with a very sharp peak at $4-5 \mathrm{~nm}$ and similar amplitude. The low-sulfur experiment has a similar shape but a much smaller amplitude. The analysis further reveals that large effects of aircraft emissions on the large-scale aerosol particle number concentration can be expected in particular for fine particles with sizes below about $20 \mathrm{~nm}$.

\section{Transport impacts on Earth's radiation budget}

\subsection{Methods}

The aerosol-radiation and aerosol-cloud coupling parameterizations implemented in the model allow us to estimate the impact of transport-induced aerosol changes on Earth's radiation budget.

Common methods to derive aerosol radiative forcing (RF) from global model results are mostly based on the analysis of the mean top-of-the-atmosphere (ToA) radiative flux differences resulting from aerosol perturbations (e.g., Lohmann and Feichter, 2005; Schulz et al., 2006). Here, we derive the aerosol RF induced by a specific transport sector as the difference in the global multi-year average ToA all-sky (cloudy and clear-sky) radiative flux $F_{\text {all }}$ between the experiments with (w) and without (wo) the emissions from the given sector:

$\mathrm{RF}_{\mathrm{all}}=F_{\mathrm{all}}^{\mathrm{w}}-F_{\mathrm{all}}^{\mathrm{wo}}$.

In order to isolate the aerosol effects, the concentrations of the radiatively active gases (other than water vapor) are kept constant in the radiation scheme of the model, and only the aerosol perturbations and the related changes in clouds and water vapor are considered. Hence, the calculated aerosol RF includes the contribution of the direct effect (scattering and absorption of radiation; Ångström, 1962), of the indirect effect (changes in cloud albedo and lifetime; Twomey, 1977; Albrecht, 1989) and of the semi-direct effect (cloud droplet evaporation due to aerosol-induced heating; Ackerman et al., 2000). A full separation of these effects would require a very large number of model experiments and is beyond the scope of the current study. Nevertheless, a rough impression on the relative importance of the direct effect compared to the total aerosol forcing can be gained by considering the clear-sky forcing:

$$
\mathrm{RF}_{\text {clear }}=F_{\text {clear }}^{\mathrm{w}}-F_{\text {clear }}^{\mathrm{wo}} \text {, }
$$




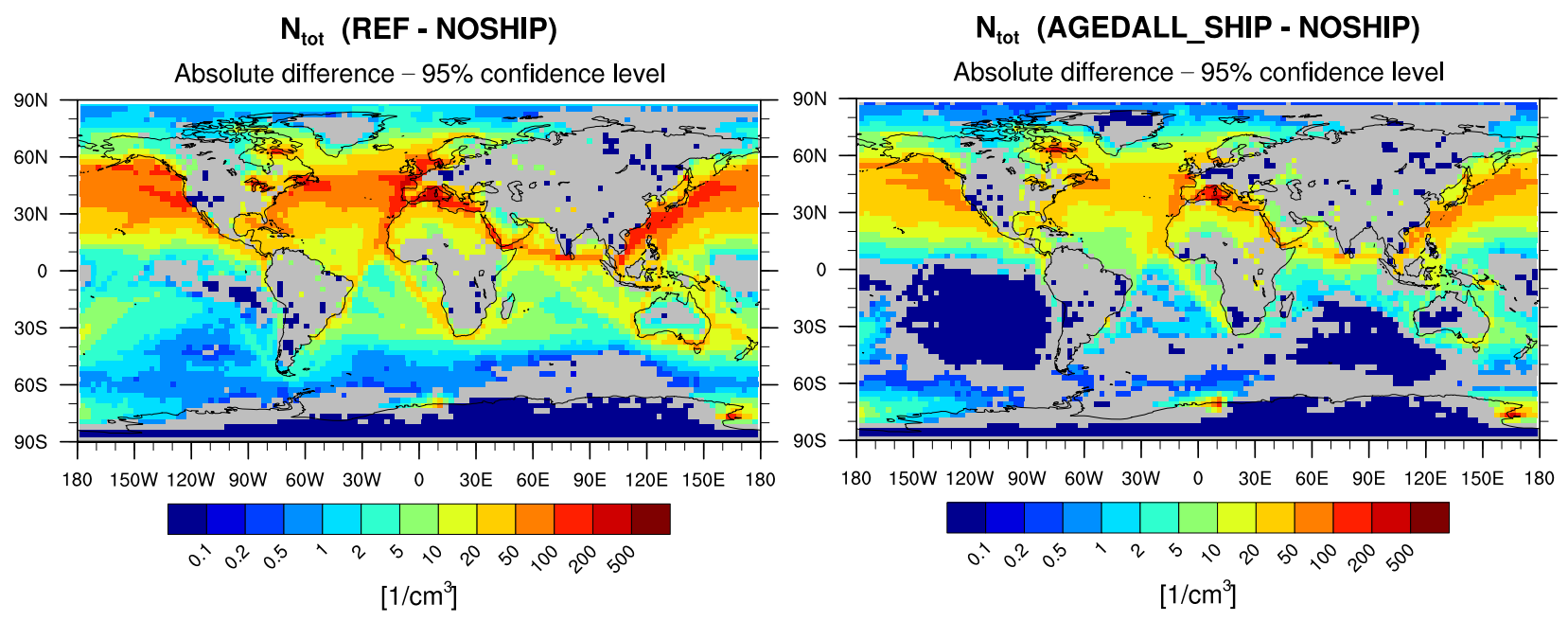

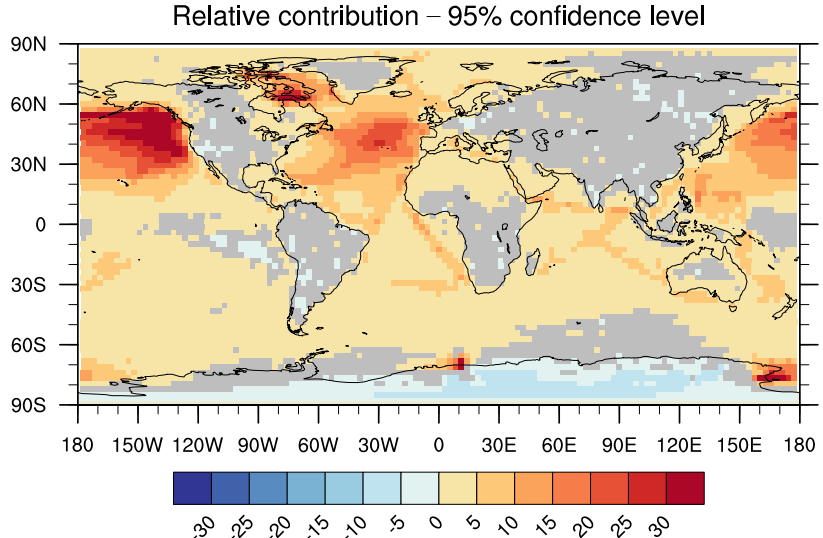

[\%]

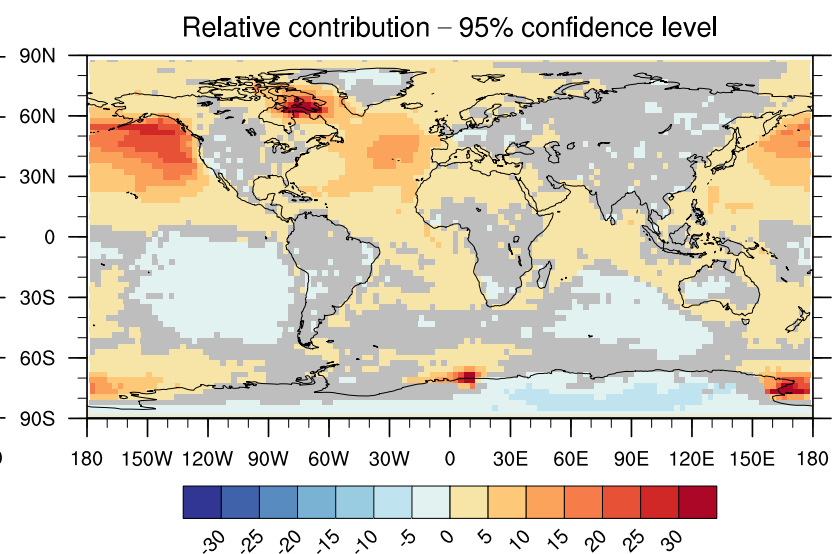

[\%]

Fig. 10. Multi-year average (1996-2005) of the absolute (top) and the relative effect (bottom) of shipping on the Aitken and accumulation mode number concentration at the surface. Plotted are the differences between the experiments AGED2_SHIP (REF) and NOSHIP (left) and between AGEDALL_SHIP and NOSHIP (right). The relative effect is calculated as the relative contribution (REF-NOSHIP)/REF (left) and (AGEDALL_SHIP-NOSHIP)/AGEDALL_SHIP (right). Grid points where the difference is not statistically significant according to a uni-variate $t$ test ( $5 \%$ error probability) are masked out in gray.

which is derived from radiative flux calculations neglecting the effects of clouds. The clear-sky forcing, however, can be modulated by feedbacks of cloud changes on other quantities, such as specific humidity or temperature, and by the related radiative impacts. The remaining forcing (i.e., the difference between $\mathrm{RF}_{\text {all }}$ and $\mathrm{RF}_{\text {clear }}$, sometimes defined as cloud forcing) can be taken as a measure of radiative effects induced by cloud changes (indirect and semi-direct effects) resulting from transport-induced aerosol perturbations.

In the following, we will discuss both all-sky and clear-sky aerosol RF. The corresponding Eqs. (5) and (6) are applied to both the shortwave (solar, $0.28-4 \mu \mathrm{m}$ in EMAC) and longwave (thermal, 3.3-1000 $\mu \mathrm{m}$ ) spectral ranges. For assessing the radiative impacts of transport-induced aerosol perturbations and for comparison with the effects of other transportinduced species, we will mainly rely on the all-sky forcing. We will use the clear-sky forcing for interpreting the results with regard to the relative importance of aerosol direct effects and aerosol-induced cloud changes.

The results of the calculations outlined above are summarized in Fig. 12 for the three transport sectors and for the various sensitivity experiments. The plotted values refer to the combined (shortwave + longwave) band. Results for the two bands separately are provided in Table $\mathrm{C} 1$. In order to put the aerosol RF results into a broader perspective, Figure 12 also shows the effects of other relevant species, as reported in the literature (see Sausen et al., 2012, for a summary). In particular, we compare aerosol impacts with the effects of $\mathrm{CO}_{2}$ (warming) and $\mathrm{NO}_{\mathrm{x}}$ emissions, the latter resulting in $\mathrm{O}_{3}$ production (warming) and loss of $\mathrm{CH}_{4}$ (cooling). In the case of aviation, the effect of contrail cirrus (warming) is considered as well. 

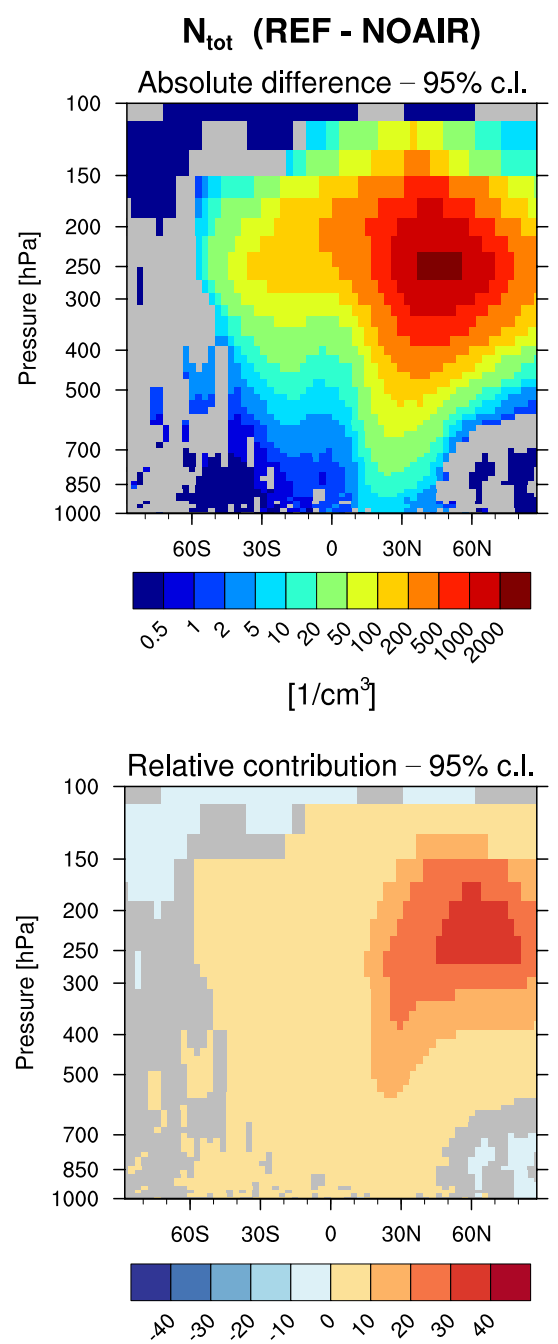

[\%]
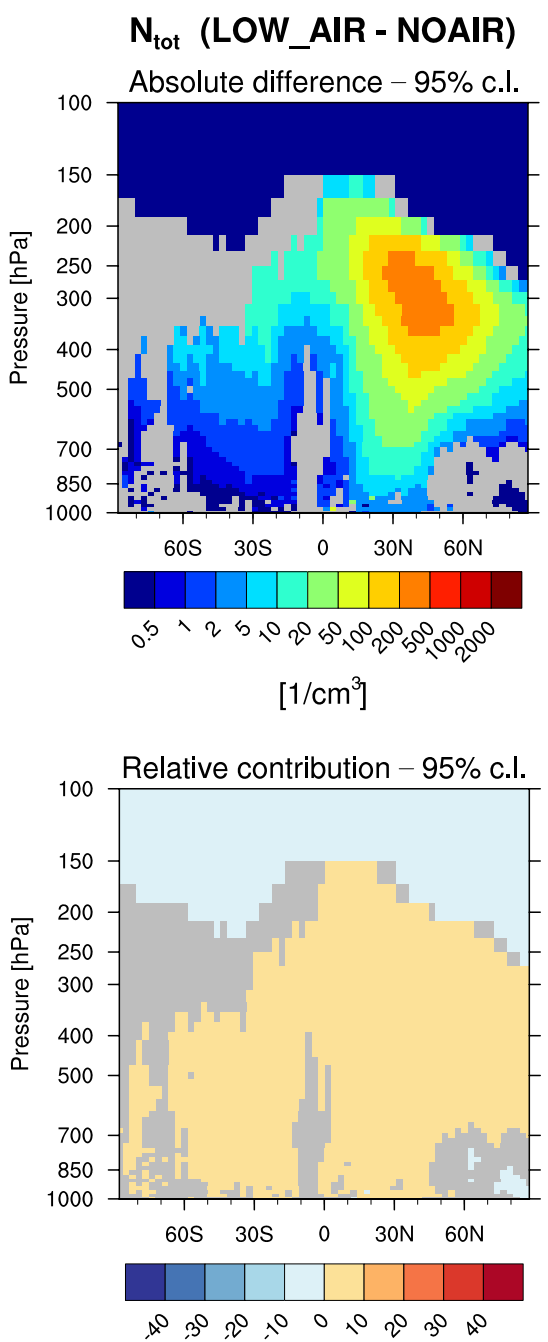

[\%]
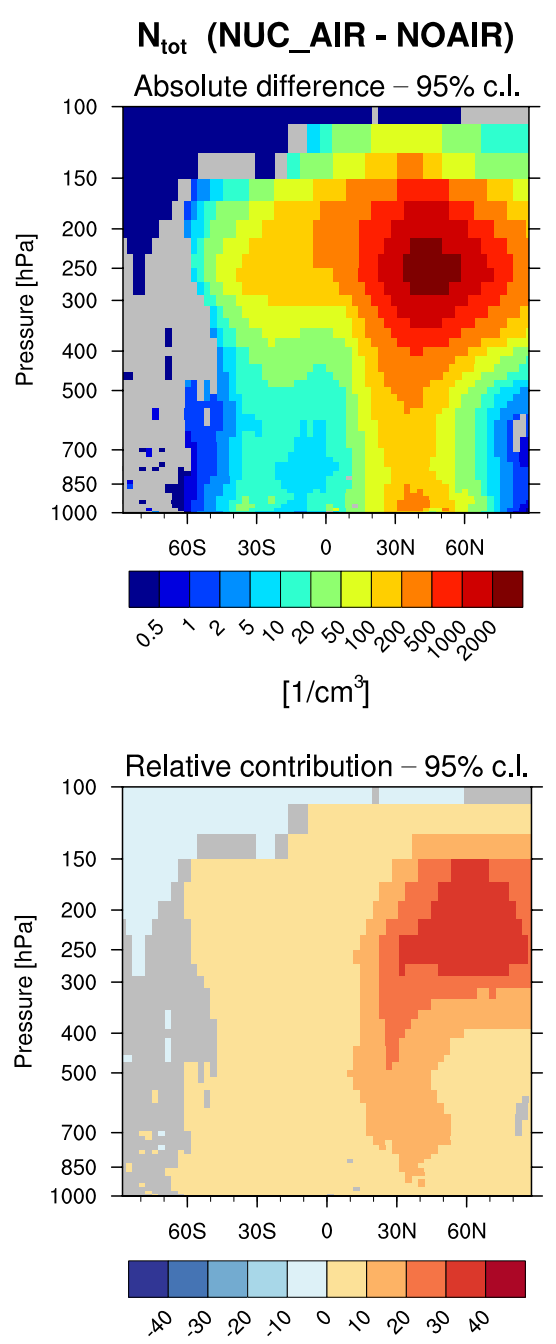

[\%]

Fig. 11. Multi-year average (1996-2005) zonal means of the absolute (top) and the relative effect (bottom) of aviation on the Aitken and accumulation mode number concentration. Plotted are the differences between the experiments HIGH_AIR (REF) and NOAIR (left), between LOW_AIR and NOAIR (middle) and between NUC_AIR and NOAIR (right). The relative effect is calculated as the relative contribution (REF-NOAIR)/REF (left), (LOW_AIR-NOAIR)/LOW_AIR (middle) and (NUC_AIR-NOAIR)/NUC_AIR (right). Grid points where the difference is not statistically significant according to a uni-variate $t$ test (5\% error probability) are masked out in gray.

\subsection{Land transport}

According to our simulations, the global aerosol RF for the land transport sector is in the range of -80.7 to $-11.8 \mathrm{~mW} \mathrm{~m}^{-2}$, depending on the assumed size distribution of emitted particles, with the upper limit of this range not statistically different from zero to a $95 \%$ confidence level. The corresponding clear-sky forcings are found to be non-significant, revealing that most of the land transport aerosol RF is due to cloud effects. A notable exception is the YOUNG_LAND experiment, for which a significant clearsky forcing is calculated (about $10 \%$ of the all-sky forcing). However, the all-sky effect is still dominated by cloudradiation interactions. In a previous model study, Balkanski et al. (2010) calculated the aerosol direct effect of road traffic and found values in the range of 29.1 to $41.4 \mathrm{~mW} \mathrm{~m}^{-2}$. The difference to our clear-sky value could be due to the fact that our value does not consider the effects of aerosol above clouds, which can be quite important for $\mathrm{BC}$ aerosol. Other reasons could be the feedback of the cloud changes on the clear-sky flux or differences in the assumed emissions. Balkanski et al. (2010) used a factor of 1.9 less BC (implying less warming) but also a factor of 2.3 less POM and of 2.2 less $\mathrm{SO}_{2}$, both resulting in much less cooling. Our results are closer to the estimate for the direct effect suggested by Fuglestvedt et al. (2008), who obtained a direct $\mathrm{RF}$ of $3.3 \pm 11 \mathrm{~mW} \mathrm{~m}^{-2}$, using similar aerosol and aerosol precursors emission totals for the land transport sector as 

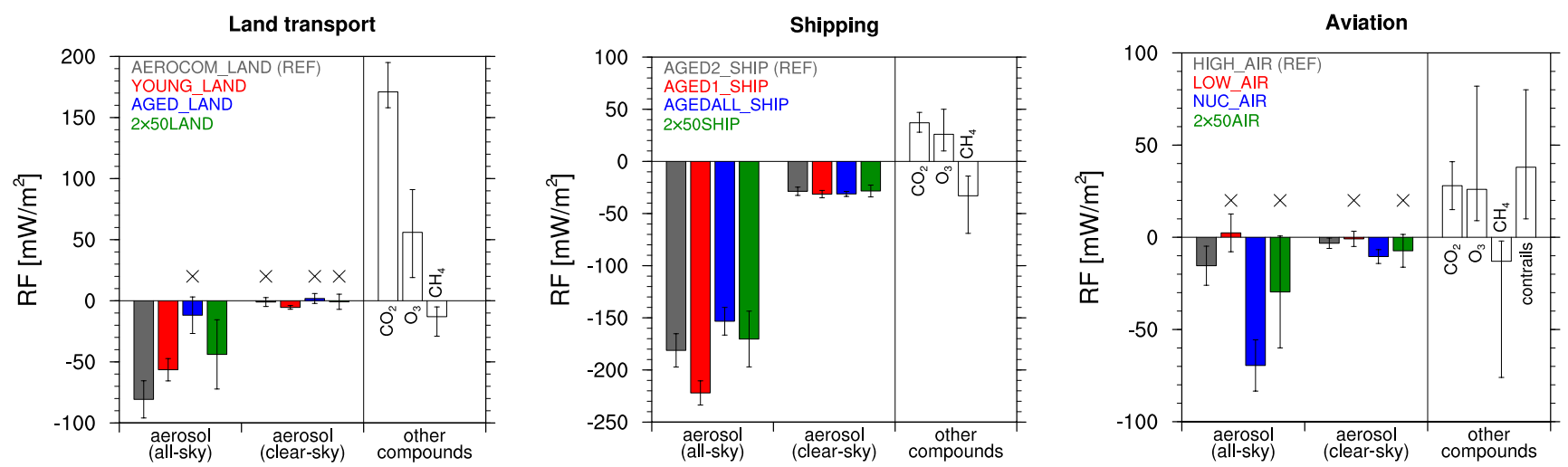

Fig. 12. Multi-year average (1996-2005) all-sky and clear-sky radiative forcings (in units of $\mathrm{mW} \mathrm{m}^{-2}$ ) of transport-induced aerosol perturbations calculated for the different model experiments. Non-significant values according to a uni-variate $t$ test (5\% error probability) are marked with the $\times$ symbol. The error bars refer to the $95 \%$ confidence intervals, based on the interannual variability of the forcings. The white bars on the right side of each panel represent the $\mathrm{RF}$ for $\mathrm{CO}_{2}$, ozone, methane and for contrail cirrus in the aviation case, as derived from other studies (see text for the corresponding references). Note the different vertical scales.

in our study. Opposite conclusions about the all-sky landtransport-induced aerosol RF were reached by Bauer and Menon (2012). Based on the GISS-MATRIX model and on the same emission inventories as in the present study, they reported a positive global total radiative forcing from land transport around $50 \mathrm{~mW} \mathrm{~m}^{-2}$ (with quite large uncertainties) resulting from the combination of indirect and semi-direct effects, while the direct effect was found to be small.

For the combination of road transport and railways, Uherek et al. (2010), based on Fuglestvedt et al. (2008), give a range of 158 to $195 \mathrm{~mW} \mathrm{~m}^{-2}$ for land-transport-induced $\mathrm{CO}_{2}, 19$ to $91 \mathrm{~mW} \mathrm{~m}^{-2}$ for $\mathrm{O}_{3}$ and -29 to $-5 \mathrm{~mW} \mathrm{~m}^{-2}$ for $\mathrm{CH}_{4}$ (year 2000 values with respect to the preindustrial times). The results of the present study reveal that the RF of land-transport-induced aerosol can be of similar magnitude as the ozone and methane effects. Furthermore, the aerosolrelated climate impacts can be significant in counteracting the warming effect of $\mathrm{CO}_{2}$ emissions.

\subsection{Shipping}

Our results reveal that shipping is the transport sector with the largest aerosol RF, in the range of -222.0 to $-153.3 \mathrm{~mW} \mathrm{~m}^{-2}$, with a dominant (between 80 and $86 \%$ ) contribution from cloud forcing. The range of cloud forcings simulated with our approach is in good agreement with the recent studies by Lauer et al. (2007), Righi et al. (2011) and Peters et al. (2012). Bauer and Menon (2012) also found a negative total radiative forcing from shipping of about $-100 \mathrm{~mW} \mathrm{~m}^{-2}$ (mostly due to the semi-direct effect), which is about a factor of 2 smaller than the values calculated by our model. A dependence of the ship-induced cloud forcing on the number of emitted particles is evident in our simulations, with the largest (smallest) value simulated for the AGED1_SHIP (AGEDALL_SHIP) simulation, which is the experiment with the largest (smallest) amount of emitted particles. This confirms the conclusions of Righi et al. (2011), who used the same assumptions about the size distributions of the emitted particles, but different emission data sets, as in the present study. Such a dependence is further supported by the results of Peters et al. (2012), who found the strongest (weakest) effect for the experiment with the largest (smallest) amount of emitted particles. The clear-sky RF obtained here is about $15-20 \%$ of the total, a conclusion also reached by Lauer et al. (2007) and Righi et al. (2011) for the direct effect. Our simulated clear-sky RF is also close to the estimate of Balkanski et al. (2010), and the RF values are pretty stable against the size distribution assumptions, due to the similar size of particles across the three assumed distributions.

Our simulations show that the aerosol effects are the major contribution to the total radiative forcing attributed to the emissions of the shipping sector. According to Eyring et al. (2010), the forcing from ship-induced $\mathrm{CO}_{2}$ is in the range of 28 to $47 \mathrm{~mW} \mathrm{~m}^{-2}$, while $\mathrm{O}_{3}$ and $\mathrm{CH}_{4}$ induce forcings in the ranges of 10 to $50 \mathrm{~mW} \mathrm{~m}^{-2}$ and -69 to $-14 \mathrm{~mW} \mathrm{~m}^{-2}$, respectively (year 2005 values with respect to preindustrial times). The large aerosol effect from shipping, however, could experience a strong reduction in the near future, due to recent regulation in shipping fuel sulfur content (Buhaug et al., 2009, see also Sect. 5.3 of the present study), which are expected to reduce both the concentration of sulfate aerosol in the marine boundary layer and the resulting cooling from the cloud albedo effect (Righi et al., 2011; Fuglestvedt et al., 2009).

\subsection{Aviation}

For aviation-induced aerosol, our model calculates an allsky $\mathrm{RF}$ in the range of -69.5 to $2.4 \mathrm{~mW} \mathrm{~m}^{-2}$, with the upper limit not statistically different from zero to a $95 \%$ 
confidence level. Also in this case, aerosol-related changes in cloud forcing have a major contribution. Significant values for the all-sky RF are simulated only in the HIGH_AIR $\left(-15.4 \mathrm{~mW} \mathrm{~m}^{-2}\right)$ and NUC_AIR $\left(-69.5 \mathrm{~mW} \mathrm{~m}^{-2}\right)$ experiments. It is interesting that, although both the HIGH_AIR and NUC_AIR experiments include significant emissions of sulfate from aircraft, the latter experiment results in a much larger cloud forcing. This is due to the larger number of emitted particles in the NUC_AIR experiment. These particles can grow and act as cloud condensation nuclei, perturbing the cloud microphysical structure and increasing the cloud albedo. This demonstrates that the assumptions on the subgrid-scale transformations of aviation-induced particles are of key relevance. To investigate which kind of clouds are substantially perturbed by aircraft emissions in this experiment, we analyzed the changes in cloud droplet and ice crystal number concentrations and effective radius induced by aviation emissions at different model levels. The results (not shown) suggest that changes in cloud droplet number concentration and effective radius primarily occur close to the surface, implying that the perturbations to low clouds are responsible for the comparatively large aviation-induced cloud effect in the NUC_AIR experiment. This is also consistent with the comparatively large aerosol particle number concentration increase in the lower troposphere obtained in this experiment (Fig. 11). The ice crystal number concentration, on the contrary, does not show remarkable changes, and only a small increase in ice particle effective radius is found around $500 \mathrm{hPa}$. It should be noted that our model considers cirrus cloud formation by homogeneous freezing of supercooled liquid solution aerosol but does not include heterogeneous nucleation of ice crystals on aircraft-generated black carbon aerosol, which is currently discussed as a potential mechanism affecting cirrus clouds (e.g., Liu et al., 2009; Hendricks et al., 2011).

A significant impact of aviation sulfate on liquid clouds at altitudes below the main cruise levels is also suggested in a recent study by Gettelman and Chen (2013) with the NCAR CAM5 global model. Previous studies on the RF impacts of aviation reported an aerosol direct effect with highly uncertain values in the range of -28 to $20 \mathrm{~mW} \mathrm{~m}^{-2}$ (Lee et al., 2010), resulting from the opposite contribution of sulfate cooling and BC warming. Unger (2011) also reported direct RF effects from individual aerosol components, with an even smaller total direct effect of only a few $\mathrm{mW} \mathrm{m}^{-2}$. The order of magnitude of the clear-sky RF calculated for the different experiments in the present work are consistent with these previous findings.

The simulated RF of aviation-induced aerosol are partly larger than the corresponding $\mathrm{CO}_{2}$ effect, from 15 to $41 \mathrm{~mW} \mathrm{~m}^{-2}$ (Lee et al., 2010) (year 2005 values with respect to preindustrial times). The effects of $\mathrm{O}_{3}$ and $\mathrm{CH}_{4}$ for aviation are very uncertain, from 9 to 82 and -76 to $-2 \mathrm{mWm}^{-2}$ (Lee et al., 2010), respectively, which makes it quite difficult to draw a conclusion on their relative importance with re- spect to the aerosol RF. However, the results of the present study show that the aerosol effect could be of the same magnitude. A similar conclusion can be drawn when comparing the aerosol effect to the contrail cirrus RF which is estimated to be in the range of 10 to $80 \mathrm{~mW} \mathrm{~m}^{-2}$ (Lee et al., 2010; Burkhardt and Kärcher, 2011).

\section{Effect of non-linearities}

Possible non-linearities in the dependence of the traffic impacts on the amount of emitted aerosol and aerosol precursor gases are discussed in this section. As detailed in Sect. 3, for each of the three sectors we performed an additional perturbation experiment, in which traffic emissions are reduced by $50 \%$ only. The resulting impact on a quantity $X$ is then scaled to a $100 \%$ reduction as assumed in the standard experiments. For example, for land transport:

$2 \times \Delta_{50}(X)=2 \times[X(\mathrm{REF})-X(50 \mathrm{LAND})]$.

This can be compared to the impact obtained by the $100 \%$ perturbation method (switching off the given transport emissions, e.g., land transport):

$\Delta_{100}(X)=[X(\mathrm{REF})-X(\mathrm{NOLAND})]$.

We interpret the difference $\Delta_{100}(X)-2 \times \Delta_{50}(X)$ as an indicator of possible non-linearities. The choice of $50 \%$ as a threshold value, in contrast to a much smaller value of $5 \%$ adopted, for example, by Hoor et al. (2009), is motivated by the necessity of extracting a statistically significant signal, given that a full decoupling of aerosol processes and model dynamics (in analogy to the chemistry-dynamics decoupling applied in chemistry-transport models) is a non-trivial task. Aerosol effects on cloud formation are considered as a key feature in the present simulations, therefore the quantification of emission-induced aerosol changes in the model output can be interfered by dynamical feedbacks.

The panels in Fig. 13 show the relative difference $\left[\Delta_{100}(X)-2 \times \Delta_{50}(X)\right] / \Delta_{100}(X)$ for the different transport sectors. Only the most relevant species for each sector are presented. For BC (shown only for land transport, top left) and POM (not shown), there is almost no significant difference between the two methods, revealing an almost linear response for all transport sectors. The other species, for which chemical processes are involved, show more significant non-linearities. For land-transport-induced $\mathrm{SO}_{4}$ (top right), the differences amount to $20-30 \%$ in the western USA and over the Arabian Peninsula. Similar values are also found for the effect of land transport emissions on aerosol nitrate and $\mathrm{NH}_{4}$ (not shown). A significant non-linear response of $\mathrm{SO}_{4}$ is seen also in the shipping case (middle left). The difference between the $\Delta_{100}(X)$ and the $2 \times \Delta_{50}(X)$ effects amounts to $10-20 \%$ in the regions where the impact was found to be relevant (see Sect. 5.3). Even stronger nonlinearities are found in the polar regions, but shipping effects 

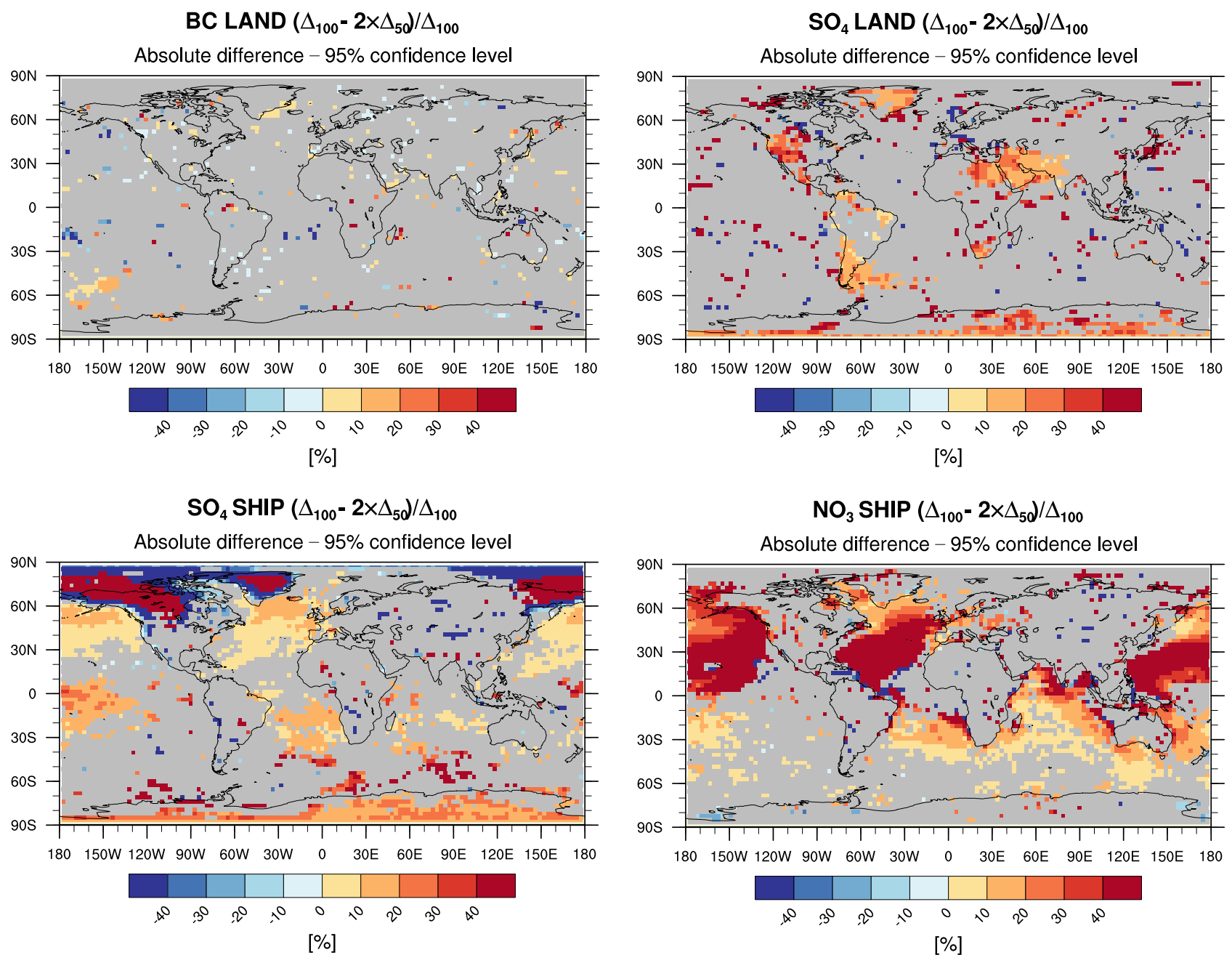

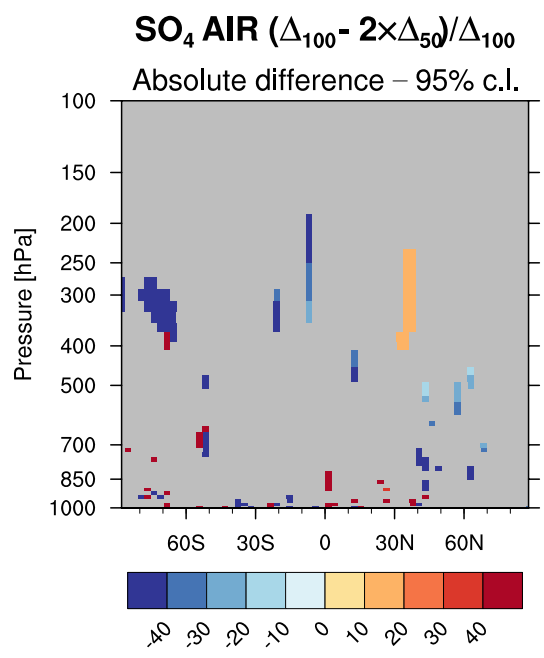

[\%]

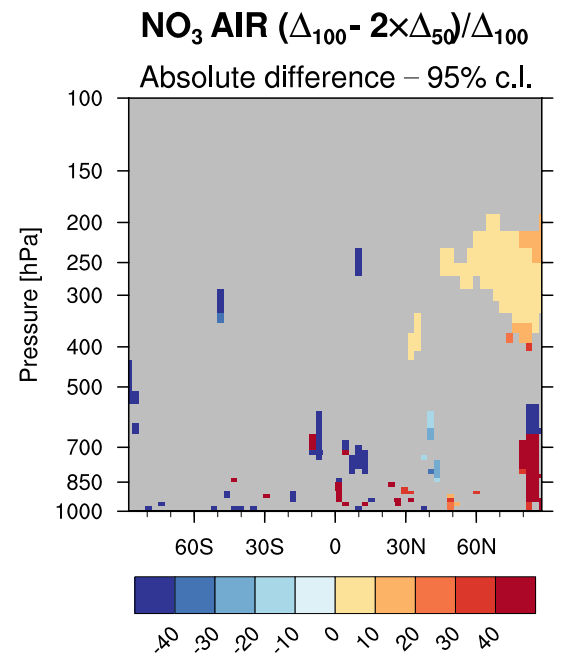

[\%]

Fig. 13. Multi-year average (1996-2005) of the relative difference $\left(\Delta_{100}-2 \times \Delta_{50}\right) / \Delta_{100}$, quantifying the effect of non-linearities on the estimated impact of the different transport sectors on aerosol concentrations. Selected species for land transport (top, surface-level concentration), shipping (middle, surface-level concentration) and aviation (bottom, zonally averaged concentration) are plotted. Grid points where the difference is not statistically significant according to a uni-variate $t$ test (5\% error probability) are masked out in gray. 
are only small in these areas. The largest non-linearities for the shipping sector are simulated for $\mathrm{NO}_{3}$ (middle right), with values larger than $40 \%$ over the oceans of the Northern Hemisphere. An important reason for these effects could be non-linearities in the formation of $\mathrm{HNO}_{3}$ from $\mathrm{OH}$ and $\mathrm{NO}_{2}$. Due to changes in the $\mathrm{OH}$ to $\mathrm{HO}_{2}$ ratio induced by changes in the $\mathrm{NO}_{\mathrm{x}}$ concentration (e.g., Seinfeld and Pandis, 1998), the $\mathrm{HNO}_{3}$ formation rate depends non-linearly on the availability of $\mathrm{NO}_{\mathrm{x}}$. This consequently leads to nonlinearities also in the formation of aerosol nitrate. In addition, it results in a strong non-linear response of aerosol ammonium (around 20-40\%, not shown) in cases when ammonium nitrate is formed. The dependence of $\mathrm{OH}$ levels on $\mathrm{NO}_{\mathrm{x}}$ can also be an important reason for the non-linearities of the $\mathrm{SO}_{4}$ response discussed above, since $\mathrm{OH}$ controls the oxidation of $\mathrm{SO}_{2}$ in the gas phase. The impacts of the aviation sector are remarkably linear for all species, with the exception of aerosol nitrate (bottom right), where non-linearities of $10-20 \%$ occur, although the number of significant points is quite small. The corresponding non-linearities in aerosol number concentration response (not shown) are found to be small for all transport sectors (mostly within 10\%) in the areas where the effects are relevant.

The non-linear response of the aerosol perturbation can of course have an impact on the RF estimated for the transport sectors. We therefore compare the RF values calculated with the $100 \%$ (REF case) and with the scaled $50 \%$ perturbation method in Fig. 12 (gray vs. green bars) and in Table C1. Significant values are found only for the land transport and shipping cases. For the latter, the response is quite linear (less than $10 \%$ deviation), whereas in the case of land transport the non-linearities seem to be important (almost a factor of 2 difference between the $100 \%$ and the scaled $50 \%$ case). No conclusions can be drawn for aviation, given the nonsignificance of the scaled RF value for this sector.

The non-linearities identified in the signals induced by land transport emissions show that the perturbation method applied here is of limited capability with regard to the quantification of transport-related contributions to atmospheric aerosol components and resulting radiative forcing. Other methods, such as tagging (Grewe, 2013), should be further developed to track aerosol effects in detailed large-scale simulations. The non-linearities also reveal that applications of the obtained results to evaluate mitigation measures by means of linear extrapolations may suffer from large uncertainties.

\section{Conclusions}

We performed global model simulations to quantify the impact of land transport, shipping and aviation emissions on global aerosol distributions (both in terms of mass and number concentrations) and to estimate the resulting effect on Earth's radiation budget. The quantification of the impacts on particle number concentration suffers from uncertainties that derive from microphysical transformations in the fresh exhaust, which cannot be resolved with the coarse spatial resolution of global climate models. To assess these uncertainties, we additionally performed a set of model experiments where subgrid-scale particle transformations are implicitly taken into account by assuming aged particle size distributions to derive the number and size of emitted particles. A further set of simulations was conducted to explore the possible non-linearities in the dependence of aerosol effects on the amount of transport emissions.

The main conclusions of this paper can be summarized as follows.

1. The effects of the three transport sectors are well separated in terms of species and spatial distribution, with different sources acting on different domains. Land transport and shipping are most relevant on continents and oceans, respectively, while the aviation impact is largely confined to the northern hemispheric upper troposphere. Overlaps of the effect of land transport and shipping occur preferentially in the coastal regions, in particular for aerosol nitrate $\left(\mathrm{NO}_{3}\right)$, which shows large changes resulting from emissions of both sectors.

2. Land transport is an extremely important source of large-scale increases of the atmospheric particulate matter concentration at the surface in the USA, Europe and the Arabian Peninsula, with relative contributions to the black carbon concentration of up to 60$70 \%$. This sector has therefore a high potential for future mitigation policies and air pollution reduction programs. In southern and eastern Asia, the land transport relative contribution to black carbon is smaller (10-20\%) since other sources, like energy production, industrial and domestic activities are dominant. The emissions from land transport also result in significant increases in the $\mathrm{NO}_{3}$ concentration over the continents in the Northern Hemisphere. The simulated land-transport-induced perturbations of the particle number concentration at surface level depend on the size distribution assumed for the emitted particles. The large-scale mean changes range between 1000 and $5000 \mathrm{~cm}^{-3}$ and 100 and $500 \mathrm{~cm}^{-3}$, deriving from the choice of two limiting cases considering size distributions typical for the urban background (with a relatively large amount of small particles) and a very aged particle population (with large particles only), respectively.

3. Sulfate and nitrate are the dominant aerosol components induced by ship emissions, with relative contributions to the large-scale mean surface-level concentration of each species ranging between 10 and $60 \%$ in the main emission regions. The effects of ship emissions on atmospheric aerosol are mainly restricted 
to the oceans and coastal areas and occur mostly in the Northern Hemisphere, where the ship traffic volume is high. Harmful impacts in terms of air pollution and human health effects can be expected, in particular for urban settlements in the vicinity of major harbors and coastal shipping routes. Hence, policies already implemented to reduce the sulfur content of shipping fuel should have beneficial effects for air quality. The uncertainty in the simulated ship-induced changes in particle number concentrations is much lower than for land transport, since more detailed information about the aging of particle populations in ship plumes is available from measurements. The simulated changes in particle numbers due to shipping show a range of uncertainty of only a factor of 2 . Increases in the mean particle number concentration of about $5-30 \%$ are obtained in the main emission areas. Since the ship-induced particles include a major fraction of large Aitken mode particles $(D>50 \mathrm{~nm})$, ship emissions could be an important source of cloud condensation nuclei over the oceans.

4. The model results reveal that aircraft emissions increase the mean mass concentration of both black carbon and sulfate by 3-5\% around the main flight levels in the northern extratropics. Even though the largest absolute effects on the aerosol mass concentrations are simulated for the lower troposphere (due to aircraft activities around major airports), the corresponding relative effects are small on the large scale. The possibly large pollution effects close to airports are much below the scales resolved by the global model applied here. The simulations reveal that aviation emissions can induce increases in the mean particle number concentration of $10-30 \%$ at the main flight altitudes in the Northern Hemisphere. These perturbations are larger than for the mass concentration, due to small-sized particles, in agreement with the findings of previous studies (e.g., Hendricks et al., 2004). The simulated number concentration impacts are more sensitive to the assumed fuel sulfur content than to the choice of size distributions characterizing the emitted particle population. The consideration of freshly nucleating exhaust particles in the model has only a small effect on the mean aircraft-induced number perturbation at cruise altitude, which on the other hand is markedly reduced when a low-sulfur fuel is considered. At lower levels the sensitivity to the size distribution assumptions is larger, resulting in an increased uncertainty in the simulated particle number effects.

5. The aerosol perturbations induced by the three transport sectors significantly alter Earth's radiation budget. Our model simulations suggest that the bulk of the transport-induced aerosol radiative forcing is attributable to aerosol-induced cloud changes for all three sectors. The strongest radiative forcing is found for shipping ( -222.0 to $-153.3 \mathrm{~mW} \mathrm{~m}^{-2}$ ), followed by land transport ( -80.7 to $-11.8 \mathrm{~mW} \mathrm{~m}^{-2}$ ) and aviation $\left(-69.5\right.$ to $\left.2.4 \mathrm{~mW} \mathrm{~m}^{-2}\right)$. These numbers reveal that aerosols are an important component in determining the climate impact of the transport sectors. The aerosol effects are comparable and often larger than the effects of $\mathrm{CO}_{2}$, ozone and methane, and should therefore be considered in future mitigation strategies.

6. The response of the aerosol distribution to the transport emissions is approximately linear for black carbon, particulate organic matter and particle number, for all transport sectors. Non-linearities are found for $\mathrm{NO}_{3}, \mathrm{NH}_{4}$ and $\mathrm{SO}_{4}$, since the amount of these aerosol components in the model depends on the efficiency of specific gas and liquid phase chemical processes which can show a highly non-linear dependence on the availability of the emitted species. This results in nonlinearities also in the aerosol-induced radiative forcing of the transport sectors, especially in the case of landbased transport. Consequently, an application of the results obtained here to evaluate mitigation measures by means of linear extrapolations can be critical.

Several improvements are desirable in order to refine the results of this work. The uncertainties due to the assumptions on subgrid-scale particle number transformations reveal that more detailed methods should be developed to address this issue. Parameterizations derived, for example, from regional model simulations and/or observational data could help to improve the representation of subgrid-scale transformation in global models. Large transport-induced increases in particle number could occur for specific particle types, like soot particles. This however could not be investigated with the current model, which does not distinguish such different particles. Further analysis with more comprehensive global aerosol models (e.g., Aquila et al., 2011) is necessary to disentangle such effects. The climate impacts of the transport sources should be analyzed in further detail, by separating the contribution of the individual aerosol components and, possibly, even of different particle types.

The present study demonstrates that aerosol changes induced by emissions from the transport sectors can be very relevant with regard to anthropogenic climate change. Since further growth of the transport sectors is expected in the near future, transport-induced aerosol changes and the resulting radiative forcing in different future scenarios should be the subject of follow-up studies. 


\section{Appendix A}

\section{The EMAC-MADE global aerosol model}

\section{A1 Model description}

The ECHAM/MESSy Atmospheric Chemistry (EMAC) model is a numerical chemistry and climate simulation system that includes submodels describing tropospheric and stratospheric processes (Jöckel et al., 2006). The Modular Earth Submodel System (MESSy) provides the framework to link multi-institutional computer codes. The core atmospheric model is the 5th generation European Centre HAMburg general circulation model (ECHAM5; Roeckner et al., 2006). EMAC (ECHAM5 version 5.3.01, MESSy version 1.4) is applied in the T42L19 spectral resolution for the present work, i.e., with a triangular truncation at great circle wave number 42 (corresponding to a Gaussian latitudelongitude grid of about $2.8^{\circ} \times 2.8^{\circ}$ ) with 19 vertical hybrid $\sigma$-pressure levels from the surface to the top model layer, centered at $10 \mathrm{hPa}(\sim 30 \mathrm{~km})$.

Aerosol microphysics is simulated using the submodel MADE (Ackermann et al., 1998) adapted for use in EMAC (Lauer et al., 2005, 2007). MADE describes the aerosol population by means of three log-normal size modes: An Aitken mode (consisting of particles smaller than about $100 \mathrm{~nm}$ ), an accumulation mode (in the size range of about $100 \mathrm{~nm}$ to $1 \mu \mathrm{m}$ ) and a coarse mode (for particles larger than about $1 \mu \mathrm{m})$. The considered aerosol components are hydrophilic and hydrophobic $\mathrm{BC}$ and $\mathrm{POM}$, sulfate $\left(\mathrm{SO}_{4}\right)$, nitrate $\left(\mathrm{NO}_{3}\right)$ and ammonium $\left(\mathrm{NH}_{4}\right)$, mineral dust, sea salt and aerosol water. The particles are assumed to be spherical and in an internal mixture. The aerosol population is simulated taking into account nucleation of new particles, condensation of sulfuric acid vapor and condensable organic compounds, and coagulation. The uptake of water and gas/particle partitioning of semi-volatile trace constituents is implemented according to Metzger et al. (2002). For the present study, in order to improve the computational efficiency, a simplified chemistry scheme is adopted including basic tropospheric background chemistry $\left(\mathrm{NO}_{\mathrm{x}}-\mathrm{HO}_{\mathrm{x}}-\mathrm{CH}_{4}-\mathrm{CO}-\mathrm{O}_{3}\right.$ chemistry) and the sulfur cycle. The prognostic equations describing chemical transformations are solved with the MECCA submodel (Sander et al., 2005). Liquid phase chemistry is calculated by the module SCAV (Tost et al., 2006). As shown by Lauer et al. (2005), a simplified chemistry scheme does not significantly affect the model's capability of reproducing the measured surface mass concentrations of the main aerosol components and their geographical distribution, although some uncertainties can occur especially for aerosol nitrate (see Appendix A2). Size- and species-dependent wet and dry deposition are simulated by the EMAC submodules SCAV (Tost et al., 2006) and DRYDEP (Kerkweg et al., 2006a), respectively.
In the configuration used for this work (Lauer et al., 2007), MADE is coupled to the radiation and cloud schemes. Aerosol activation and resulting cloud microphysical processes are described by the parameterization of AbdulRazzak and Ghan (2000), coupled to the two-moment microphysical cloud scheme by Lohmann et al. (1999) and Lohmann (2002). Aerosol optical depth, single scattering albedo and asymmetry factor are calculated according to the Mie theory as a function of aerosol size and chemical composition and form the input to the EMAC radiation scheme. The radiation scheme, on the other hand, is decoupled from the model chemistry; greenhouse gas concentrations are prescribed using an offline climatology for ozone (Fortuin and Kelder, 1998) and constant values representative of the year 2000 for the other gases $\left(\mathrm{CO}_{2}, \mathrm{CH}_{4}, \mathrm{~N}_{2} \mathrm{O}, \mathrm{CFC}-11\right.$ and CFC12).

\section{A2 Model evaluation}

An extensive evaluation of EMAC-MADE was performed by Lauer et al. $(2005,2007)$ and Aquila et al. (2011). They concluded that the model reproduces aerosol mass concentrations, their seasonal cycle and geographical distribution reasonably well, with differences between model and observations mostly within a factor of two. Larger discrepancies were found for aerosol nitrate, likely due to the use of a simplified chemistry scheme in the model. Number concentrations are also well simulated by the model, which is able to capture the differences between Northern and Southern hemispheres and, most importantly for the goals of the present study, between clean and polluted areas, with a good performance at all altitude levels of the troposphere.

With respect to the aforementioned studies, a different set of emission inventories is implemented here (see Sect. 2). Although a qualitative comparison with the results of Lauer et al. (2007) and Aquila et al. (2011) does not show striking differences in the distribution of aerosol mass and number concentration, the model performance is further evaluated here by comparing aerosol concentrations with upto-date station data, focusing on the regions of the globe characterized by high anthropogenic emissions. Following a similar method as adopted by Pringle et al. (2010) and Pozzer et al. (2012), we consider data from the European Monitoring and Evaluation Programme (EMEP; Hjellbrekke and Fjæraa, 2011) for Europe, the Clean Air Status and Trends NETwork (CASTNET; Edgerton et al., 1990) and the Interagency Monitoring of PROtected Visual Environments (IMPROVE; Hand et al., 2011) for North America, and the Acid deposition monitoring NETwork in East Asia (EANET; Totsuka et al., 2005) for Asia. Additionally, aerosol optical depth (AOD) is evaluated by comparison with the global sun photometer data of the AErosol RObotic NETwork (AERONET; Holben et al., 1998a, b). Since MADE calculates AOD at a wavelength $\lambda=550 \mathrm{~nm}$, the AERONET values of the Angstrom exponent $(440 / 870 \mathrm{~nm})$ and of the 
Table A1. Summary of the comparison between model $(m)$ and observations $(o)$ for aerosol concentrations (EMEP, CASTNET, IMPROVE, EANET) and aerosol optical depth (AOD) at $550 \mathrm{~nm}$ (AERONET). Average $\bar{x}$ and standard deviation $\sigma$ (in units of $\mu \mathrm{g} \mathrm{m}^{-3}$, except AOD, which is dimensionless) are computed over all available observational data points $N_{\text {points }}$ in the time period 1996-2005. The standard deviation accounts for both temporal and spatial variations. $\%_{\text {factor } 2}$ represents the percentage fraction of model data points showing simulated values within a factor of 2 of the observations. The different number of points for the different species is due to differences in station coverage and data availability.

\begin{tabular}{llrrrrrrr}
\hline & Network & $N_{\text {points }}$ & $\bar{x}_{m}$ & $\sigma_{m}$ & $\bar{x}_{o}$ & $\sigma_{o}$ & $\bar{x}_{m} / \bar{x}_{o}$ & $\%_{\text {factor2 }}$ \\
\hline \multirow{3}{*}{$\mathrm{SO}_{4}$} & EMEP & 9172 & 3.98 & 2.71 & 2.26 & 1.70 & 1.76 & 55.1 \\
& CASTNET & 8215 & 4.70 & 3.67 & 3.15 & 2.38 & 1.49 & 72.3 \\
& IMPROVE & 13162 & 3.11 & 2.81 & 1.61 & 1.72 & 1.94 & 44.8 \\
& EANET & 1276 & 4.18 & 3.21 & 3.42 & 4.88 & 1.22 & 56.5 \\
\hline \multirow{2}{*}{$\mathrm{NO}_{3}$} & EMEP & 3701 & 1.22 & 1.30 & 1.63 & 1.82 & 0.75 & 38.1 \\
& CASTNET & 8215 & 0.70 & 0.82 & 0.87 & 1.07 & 0.80 & 33.4 \\
& IMPROVE & 13162 & 0.50 & 0.68 & 0.50 & 0.75 & 1.02 & 28.0 \\
& EANET & 1247 & 0.80 & 1.31 & 0.99 & 2.08 & 0.81 & 21.3 \\
$\mathrm{NH}_{4}$ & EMEP & 3513 & 1.74 & 1.20 & 0.96 & 0.90 & 1.81 & 50.6 \\
& CASTNET & 8215 & 1.49 & 0.88 & 1.10 & 0.77 & 1.35 & 71.9 \\
& IMPROVE & 609 & 1.58 & 0.66 & 1.16 & 0.56 & 1.36 & 81.6 \\
$\mathrm{BC}^{*}$ & EANET & 1256 & 1.55 & 1.12 & 0.94 & 1.50 & 1.66 & 38.2 \\
\hline $\mathrm{POM}^{*}$ & IMPROVE & 13106 & 0.29 & 0.33 & 0.27 & 0.27 & 1.10 & 65.0 \\
\hline \multirow{2}{*}{$\mathrm{PM}_{10}$} & IMPROVE & 13106 & 1.95 & 1.88 & 1.72 & 2.01 & 1.13 & 55.9 \\
\hline \multirow{2}{*}{$\mathrm{PM}_{2.5}$} & EMEP & 3132 & 14.87 & 6.03 & 17.18 & 8.91 & 0.87 & 85.9 \\
\hline $\mathrm{AOD}_{550}$ & IMPROVE & 13087 & 11.39 & 8.08 & 10.76 & 7.17 & 1.06 & 71.2 \\
\hline & IMPROP & 1641 & 12.19 & 4.73 & 11.35 & 7.29 & 1.07 & 82.5 \\
\hline
\end{tabular}

AOD at $440 \mathrm{~nm}$ are used to derive the AOD at $550 \mathrm{~nm}$ (see e.g., Santese et al., 2010).

The comparison between model and observations is performed using all observational data available for the simulated period (1996-2005), on a monthly-mean basis. Model data is extracted for the grid boxes where the respective observational stations are located (co-located model and observational data) considering only those time periods covered by the observations. The relevant statistics for the resulting points are collected in Table A1. In general, a reasonable agreement between model and observations is found. The ratio between model and observational averages is within a factor of two for all species and a large fraction of the concentrations and AODs modeled for the individual points lies within a factor of two compared to the corresponding observed values. The performance of EMAC-MADE according to this comparison is in line with the results of other global aerosol models (Pringle et al., 2010; Pozzer et al., 2012).

We find a particularly good agreement between model and observations for $\mathrm{PM}_{10}$ and $\mathrm{PM}_{2.5}$ and for AOD (Table A1). The largest discrepancies are found for $\mathrm{NO}_{3}$, with less than $40 \%$ of the points showing modeled concentrations within a factor of two of the observations. As stated above, this could be due to the simplified chemical mechanism adopted for our simulations. Interestingly, a relatively poor agreement for $\mathrm{NO}_{3}$ (compared to other species) was also reported by Pozzer et al. (2012) using EMAC coupled to a different aerosol model (GMXe, Pringle et al., 2010), at higher resolution and with a different set of emissions. Pozzer et al. (2012) noted that such discrepancy could be possibly due to measurement biases in the station networks related to the use of Teflon filters to determine nitrate concentrations. Difficulties in the evaluation of nitrate concentration in a global model were also reported by Bauer et al. (2007), who ascribed them to the relatively short lifetime of aerosol nitrate, which can lead to large concentration gradients on spatial scales much smaller than the typical resolution of a global model (several hundreds kilometers). Other authors (Pye et al., 2009) suggested that $\mathrm{NH}_{3}$ emissions could be a significant source of uncertainty for nitrate predictions. 
Table B1. Assumed size distributions and resulting mass splitting and total particle number emissions for the reference and sensitivity experiments. The nucleation, Aitken and accumulation modes are indicated by NUC, AKN and ACC, respectively. The nucleation and Aitken modes are both assigned to the Aitken mode of MADE. The size distribution parameters for each size mode are given in Table 1.

\begin{tabular}{|c|c|c|c|c|c|c|c|c|}
\hline \multirow[b]{2}{*}{ Sector } & \multicolumn{2}{|c|}{ Size distribution } & \multicolumn{3}{|c|}{ Mass splitting [\%] } & \multicolumn{3}{|c|}{ Number emissions $\left[10^{25} \mathrm{a}^{-1}\right]$} \\
\hline & Name & Size modes & NUC & $\mathrm{AKN}$ & $\mathrm{ACC}$ & NUC & $\mathrm{AKN}$ & $\mathrm{ACC}$ \\
\hline Biomass burning & aerocom & D06 ACC & 0 & 0 & 100 & 0 & 0 & 1996 \\
\hline Agric. waste burning & aerocom & D06 ACC & 0 & 0 & 100 & 0 & 0 & 62.57 \\
\hline Anthrop. non-transport & aerocom_land & D06 AKN & 0 & 100 & 0 & 0 & 18973 & 0 \\
\hline Anthrop. non-transport & young_land & B09 NUC/AKN & 6.7 & 93.3 & 0 & 7864 & 4522 & 0 \\
\hline Anthrop. non-transport & aged_land & B09 AKN/ACC & 0 & 10.0 & 90.0 & 0 & 483.9 & 315.6 \\
\hline Land transport & aerocom_land & D06 AKN & 0 & 100 & 0 & 0 & 3607 & 0 \\
\hline Land transport & young_land & B09 NUC/AKN & 6.7 & 93.3 & 0 & 1495 & 859.7 & 0 \\
\hline Land transport & aged_land & B09 AKN/ACC & 0 & 10.0 & 90.0 & 0 & 92.00 & 60.00 \\
\hline Shipping & aged2_ship & AGED2 AKN/ACC & 0 & 79.6 & 20.4 & 0 & 107.0 & 0.798 \\
\hline Shipping & aged1_ship & AGED1 AKN/ACC & 0 & 95.5 & 4.5 & 0 & 190.9 & 0.119 \\
\hline Shipping & agedall_ship & D06 ACC & 0 & 0 & 100 & 0 & 0 & 35.42 \\
\hline Aviation & high_air & P99 (high S) & 0 & 91.4 & 8.6 & 0 & 24.54 & 0.008 \\
\hline Aviation & low_air & P99 (low S) & 0 & 91.4 & 8.6 & 0 & 10.11 & 0.003 \\
\hline \multirow[t]{2}{*}{ Aviation } & nuc_air & P99 (BC) & 0 & 91.4 & 8.6 & 0 & 10.02 & 0.003 \\
\hline & & $\mathrm{K} 07 \mathrm{NUC}\left(\mathrm{SO}_{4}\right)$ & 100 & 0 & 0 & 10614 & 0 & 0 \\
\hline
\end{tabular}

\section{Appendix B}

\section{Size distributions of emitted particles}

This section discusses the details of the assumed size distributions of the particles emitted by the three sectors (Sect. 2.2). For each sector, the size distribution details for the reference and two sensitivity experiments are presented. The resulting splitting of emitted mass in the size modes of MADE and the total number of particles emitted in each mode for the different experiments are summarized in Table B1.

\section{B1 Land transport}

AEROCOM_LAND (identical to REF): for the reference experiment, the AeroCom recommendations (D06) are followed, assigning land transport and anthropogenic nontransport emissions to the Aitken mode, with a median diameter of $30 \mathrm{~nm}$ (aerocom_land size distribution). This is in reasonable agreement with the size distribution of particles in the nucleation and Aitken mode size range observed by B09 under urban background conditions (Table 1). However, the observed distribution in this size range is wider and clearly shows a bimodal structure. The effects of these discrepancies are investigated in a targeted sensitivity study, described in the following.

YOUNG_LAND: B09 provides a trimodal fit to the size distribution of background aerosol in urban areas. This is characterized by a nucleation/young Aitken mode (mostly sulfate and volatile compounds), an Aitken mode (mostly soot) and an accumulation mode, with median diameters of 18,58 and $138 \mathrm{~nm}$, respectively (considering the median values of all measured distributions). For this first sensitivity simulation, the emissions are assigned to the first two modes of B09 (young_land size distribution). However, these will be both part of the MADE Aitken mode (since MADE does not include an explicit nucleation mode). Therefore the AEROCOM_LAND and YOUNG_LAND experiments are identical in terms of mass splitting, while there are differences in terms of number emissions. In particular, the ratio between the total emitted numbers in these two cases is about 1.5 (calculated considering number emissions from land transport in all size modes, as given in Table B1).

AGED_LAND: to characterize a more aged aerosol population for land transport and anthropogenic non-transport emissions, this sensitivity experiment assumes that particles are described by both the Aitken and the accumulation mode of B09 (aged_land size distribution). With respect to the reference case, the median diameter of the particles is larger, resulting in about 24 times less particles (Table B1).

\section{B2 Shipping}

AGED2_SHIP (identical to REF): as a reference case, the AGED2 distribution of Righi et al. (2011) is used in this simulation, based on the measurements of Petzold et al. (2008). Particle diameters in this size distribution are relatively large and describe the conditions in a ship plume about $1 \mathrm{~h}$ after emission. Due to coagulation with comparatively large soot 
Table C1. Multi-year average (1996-2005) all-sky and clear-sky radiative forcings (in units of $\mathrm{mW} \mathrm{m}^{-2}$ ) of transport-induced aerosol perturbations calculated for the different model experiments. The results are shown for the shortwave, longwave and combined (shortwave + longwave) bands. Significant values according to a uni-variate $t$ test (5\% error probability) are marked in bold. The $95 \%$ confidence intervals are provided for the combined band. Note that due to rounding, the values for the combined bands may deviate from the sum of the corresponding shortwave and longwave values. The values for the combined band correspond to the radiative forcings presented in Fig. 12 .

\begin{tabular}{|c|c|c|c|c|c|c|}
\hline \multirow[b]{2}{*}{ Name } & \multicolumn{2}{|c|}{ Shortwave } & \multicolumn{2}{|c|}{ Longwave } & \multicolumn{2}{|c|}{ Shortwave + Longwave } \\
\hline & $\mathrm{RF}_{\mathrm{all}}$ & $\mathrm{RF}_{\text {clear }}$ & $\mathrm{RF}_{\text {all }}$ & $\mathrm{RF}_{\text {clear }}$ & $\mathrm{RF}_{\text {all }}$ & $\mathrm{RF}_{\text {clear }}$ \\
\hline AEROCOM_LAND (REF) & -87.4 & -7.9 & 6.6 & 6.9 & $-80.7 \pm 15.2$ & $-1.0 \pm 3.7$ \\
\hline YOUNG_LANDD & $-\mathbf{5 5 . 5}$ & -6.8 & -0.9 & 1.3 & $-56.5 \pm 9.2$ & $-5.4 \pm 1.5$ \\
\hline AGED_LAND & -11.7 & 0.2 & -0.1 & 1.7 & $-11.8 \pm 15.0$ & $1.9 \pm 4.0$ \\
\hline $2 \times 50 \mathrm{LAND}$ & -49.1 & -6.3 & 5.2 & 5.5 & $-43.9 \pm 28.4$ & $-0.8 \pm 6.2$ \\
\hline AGED2_SHIP (REF) & -190.4 & -34.4 & 9.1 & 5.7 & $-181.2 \pm 16.0$ & $-28.7 \pm 4.0$ \\
\hline AGED1_SHIP & -231.9 & -35.4 & 9.9 & 4.0 & $-222.0 \pm 11.6$ & $-31.4 \pm 3.5$ \\
\hline AGEDALL_SHIP & -158.5 & -35.1 & 5.3 & 3.9 & $-153.3 \pm 13.3$ & $-31.2 \pm 2.4$ \\
\hline $2 \times 50 \mathrm{SHIP}^{-}$ & -176.6 & -33.2 & 6.3 & 4.8 & $-170.3 \pm 26.7$ & $-28.4 \pm 5.7$ \\
\hline HIGH_AIR (REF) & -16.8 & -5.6 & 1.3 & 2.4 & $-15.4 \pm 10.6$ & $-3.2 \pm 2.8$ \\
\hline LOW_AIR & 4.9 & -1.0 & -2.5 & 0.2 & $2.4 \pm 10.2$ & $-0.8 \pm 4.1$ \\
\hline NUC_AIR & -70.8 & -13.8 & 1.3 & 3.3 & $-69.5 \pm 13.9$ & $-10.5 \pm 3.8$ \\
\hline $2 \times 50 \mathrm{AIR}$ & -29.2 & -7.2 & -0.4 & -0.1 & $-29.7 \pm 30.3$ & $-7.3 \pm 8.9$ \\
\hline
\end{tabular}

particles emitted by ship engines, aerosol particles in the nucleation mode size range are removed quite rapidly in the plume. This is the reason for the large particle diameters assumed for ship-induced particles.

AGED1_SHIP: Righi et al. (2011) also considered a second set of parameters, named AGED1, characterized by slightly different measured values, still describing an aged ship plume. These result in a different mass splitting with respect to AGED2_SHIP (Aitken/accumulation 96/4\% versus $80 / 20 \%$ ) and in a factor of about 1.7 more particles (Table B1).

AGEDALL_SHIP: as an extreme case, the effects of assuming a very aged aerosol population (agedall_ship size distribution) are investigated in this experiment. All particles are assigned to the accumulation mode, with a median diameter of $80 \mathrm{~nm}$ (as in D09). The resulting total number is about a factor of 3 less than in the reference AGED2_SHIP case (Table B1).

\section{B3 Aviation}

HIGH_AIR (identical to REF): we consider a size distribution measured by P99 in the exhaust plume of a B737-300 aircraft. The age of the observed plume was less than $1 \mathrm{~s}$. The measured size distribution includes an Aitken mode, composed of primary BC particles with a median diameter of $25 \mathrm{~nm}$, and an accumulation mode of larger particles $(150 \mathrm{~nm})$. For aircraft-generated BC particles, a vertical variation of the number-to-mass ratio (Hendricks et al., 2004) is additionally assumed. The fuel sulfur content during the P99 experiment was very low $\left(2.6 \mathrm{mg}(\mathrm{S}) \mathrm{kg}_{\text {fuel }}^{-1}\right)$, corresponding to an emission index of $0.0052 \mathrm{~g}\left(\mathrm{SO}_{2}\right) \mathrm{kg}_{\text {fuel }}^{-1}$, and different from the value assumed here $\left(0.8 \mathrm{~g}\left(\mathrm{SO}_{2}\right) \mathrm{kg}_{\text {fuel }}^{-1}\right.$; Lee et al., 2010).

LOW_AIR: the fuel sulfur content in jet fuels is expected to decrease in the future, as a strategy to improve air quality near airports (Unger, 2011). A simulation with a reduced fuel sulfur content of $2.6 \mathrm{mg}(\mathrm{S}) \mathrm{kg}_{\text {fuel }}^{-1}$ is performed in this sensitivity study, according to P99.

NUC_AIR: according to the simulations of K07, nucleation mode particles (size of about $3 \mathrm{~nm}$ ) have still survived in the aircraft plume after $24 \mathrm{~h}$. This is mainly due to the swift plume dilution, which leads to an inefficient coagulation. This sensitivity experiment considers the nucleation mode as described by $\mathrm{K} 07$ for sulfate particles. BC particles, on the other hand, are assigned according to P99 as in the reference simulation. This assumption generates a large number of particles and can be regarded as a maximum estimate for the number of emitted particles, in contrast to the reference simulation which can be considered as a minimum estimate, because it does not include nucleating particles. Since K07 does not provide fitting parameters for the nucleation mode, a median wet diameter of $3.5 \mathrm{~nm}$ and a standard deviation of 1.7 , consistently with the nucleation scheme of MADE (see e.g., Aquila et al., 2011), are used. The conversion from wet to dry diameter is realized considering the typical ratio $D_{\text {wet }} / D_{\text {dry }}$ (for $D_{\text {wet }}<10 \mathrm{~nm}$ ) in the North Atlantic flight corridor (45$60^{\circ} \mathrm{N}, 10-55^{\circ} \mathrm{W}$ and $10-12 \mathrm{~km}$ altitude) as simulated in the reference experiment. Typical ratios are within the range 1.21.6 , with an average of about 1.4. This gives a median dry diameter for the nucleation mode: $D_{\text {dry }}=3.5 \mathrm{~nm} / 1.4=2.5 \mathrm{~nm}$. The fuel sulfur content in this experiment is the same as in the reference simulation. 


\section{Appendix C}

\section{Transport-induced aerosol RF effects}

The aerosol radiative forcing effects induced by transport emissions were discussed in Sect. 7 and the results for the combined shortwave+longwave bands were summarized in Fig. 12. Table $\mathrm{C} 1$ provides the corresponding values, including the shortwave and longwave bands separately.

\section{Appendix D}

Acronyms and abbreviations

\begin{tabular}{|c|c|}
\hline AERONET & AErosol RObotic NETwork \\
\hline AGAGE & $\begin{array}{l}\text { Advanced Global Atmospheric Gases Ex- } \\
\text { periment }\end{array}$ \\
\hline AOD & Aerosol Optical Depth \\
\hline $\mathrm{BC}$ & Black Carbon \\
\hline CAM & Community Aerosol Model \\
\hline CASTNET & Clean Air Status and Trends NETwork \\
\hline CMIP5 & $\begin{array}{l}\text { Climate Model Intercomparison Project } \\
\text { Phase } 5\end{array}$ \\
\hline DMS & DiMethyl Sulfide \\
\hline DRYDEP & DRY DEPosition submodule in MESSy \\
\hline EANET & $\begin{array}{l}\text { Acid deposition monitoring NETwork in } \\
\text { East Asia }\end{array}$ \\
\hline ECHAM5 & $\begin{array}{l}\text { European Centre HAMburg general circu- } \\
\text { lation model version } 5\end{array}$ \\
\hline ECMWF & $\begin{array}{l}\text { European Centre for Medium-range } \\
\text { Weather Forecast }\end{array}$ \\
\hline EMAC & $\begin{array}{l}\text { ECHAM/MESSy Atmospheric Chemistry } \\
\text { model }\end{array}$ \\
\hline EMEP & $\begin{array}{l}\text { European Monitoring and Evaluation Pro- } \\
\text { gramme }\end{array}$ \\
\hline GMXe & Global Modal-aerosol eXtension \\
\hline ICOADS & $\begin{array}{l}\text { International Comprehensive Ocean- } \\
\text { Atmosphere Data Set }\end{array}$ \\
\hline IMO & International Maritime Organization \\
\hline IMPROVE & $\begin{array}{l}\text { Interagency Monitoring of PROtected Vi- } \\
\text { sual Environments }\end{array}$ \\
\hline IPCC & $\begin{array}{l}\text { Intergovernmental Panel on Climate } \\
\text { Change }\end{array}$ \\
\hline MADE & $\begin{array}{l}\text { Modal Aerosol Dynamics model for Eu- } \\
\text { rope (adapted for global applications) }\end{array}$ \\
\hline MECCA & $\begin{array}{l}\text { Module Efficiently Calculating the Chem- } \\
\text { istry of the Atmosphere }\end{array}$ \\
\hline MESSy & Modular Earth Submodel System \\
\hline NCAR & National Center for Atmospheric Research \\
\hline NMHC & Non-Methane HydroCarbons \\
\hline OC & Organic Carbon \\
\hline OECD & $\begin{array}{l}\text { Organization for Economical Cooperation } \\
\text { and Development }\end{array}$ \\
\hline
\end{tabular}

\begin{tabular}{|c|c|}
\hline $\mathrm{OM}$ & Organic Matter \\
\hline PM & Particulate Matter \\
\hline POM & Particulate Organic Matter \\
\hline QUANTIFY & $\begin{array}{l}\text { Quantifying the Climate Impact of Global } \\
\text { and European Transport Systems }\end{array}$ \\
\hline RCP & Representative Concentration Pathway \\
\hline $\mathrm{RF}$ & Radiative Forcing \\
\hline SCAV & SCAVenging submodel in MESSy \\
\hline SECA & Sulfur Emissions Control Area \\
\hline
\end{tabular}

Acknowledgements. This study has been conducted in the framework of the DLR project VEU and of the EU projects TRANSPHORM and REACT4C. The aerosol model MADE was originally developed by the University of Cologne, Germany (RIU/EURAD project). We are grateful to the whole MESSy team for the development of EMAC, to Patrick Jöckel for his help with the model setup and to Bernd Kärcher for stimulating discussions. We thank Michael Ponater, Veronika Eyring and Christopher Kaiser for their valuable comments on the manuscript draft, and the two anonymous reviewers for their constructive suggestions. The provision of observational data by the EMEP, CASTNET, IMPROVE, EANET and AERONET networks is kindly acknowledged. The CMIP5 emission data have been downloaded from the IIASA website at http://www.iiasa.ac.at/web-apps/tnt/RcpDb.

The service charges for this open access publication have been covered by a Research Centre of the Helmholtz Association.

Edited by: H. Tost

\section{References}

Abdul-Razzak, H. and Ghan, S. J.: A parameterization of aerosol activation 2. Multiple aerosol types, J. Geophys. Res., 105, 68376844, doi:10.1029/1999JD901161, 2000.

Ackermann, I. J., Hass, H., Memmesheimer, M., Ebel, A., Binkowski, F. S., and Shankar, U.: Modal aerosol dynamics model for Europe: Development and first applications, Atmos. Environ., 32, 2981-2999, 1998.

Ackerman, A. S., Toon, O. B., Stevens, D. E., Heymsfield, A. J., Ramanathan, V., and Welton, E. J.: Reduction of tropical cloudiness by soot, Science, 288, 1042-1047, doi:10.1126/science.288.5468.1042, 2000.

Albrecht, B. A.: Aerosols, cloud microphysics, and fractional cloudiness, Science, 245, 1227-1230, doi:10.1126/science.245.4923.1227, 1989.

Ångström, A.: Atmospheric turbidity, global illumination and planetary albedo of the earth, Tellus, 14, 435-450, doi:10.1111/j.2153-3490.1962.tb01356.x, 1962.

Aquila, V., Hendricks, J., Lauer, A., Riemer, N., Vogel, H., Baumgardner, D., Minikin, A., Petzold, A., Schwarz, J. P., Spackman, J. R., Weinzierl, B., Righi, M., and Dall'Amico, M.: MADE-in: a new aerosol microphysics submodel for global simulation of insoluble particles and their mixing state, Geosci. Model Dev., 4, 325-355, doi:10.5194/gmd-4-325-2011, 2011.

Balkanski, Y., Myhre, G., Gauss, M., Rädel, G., Highwood, E. J., and Shine, K. P.: Direct radiative effect of aerosols emitted by 
transport: from road, shipping and aviation, Atmos. Chem. Phys., 10, 4477-4489, doi:10.5194/acp-10-4477-2010, 2010.

Barrett, S. R. H., Britter, R. E., and Waitz, I. A.: Global mortality attributable to aircraft cruise emissions, Environ. Sci. Tech., 44, 7736-7742, doi:10.1021/es101325r, 2010.

Bauer, S. E. and Menon, S.: Aerosol direct, indirect, semidirect, and surface albedo effects from sector contributions based on the IPCC AR5 emissions for preindustrial and present-day conditions, J. Geophys. Res., 117, 1-15, doi:10.1029/2011JD016816, 2012.

Bauer, S. E., Koch, D., Unger, N., Metzger, S. M., Shindell, D. T., and Streets, D. G.: Nitrate aerosols today and in 2030: a global simulation including aerosols and tropospheric ozone, Atmos. Chem. Phys., 7, 5043-5059, doi:10.5194/acp-7-5043-2007, 2007.

Birmili, W., Alaviippola, B., Hinneburg, D., Knoth, O., Tuch, T., Borken-Kleefeld, J., and Schacht, A.: Dispersion of trafficrelated exhaust particles near the Berlin urban motorway - estimation of fleet emission factors, Atmos. Chem. Phys., 9, 23552374, doi:10.5194/acp-9-2355-2009, 2009.

Buhaug, O., Corbett, J. J., Endresen, O., Eyring, V., Faber, J., Hanayama, S., Lee, D. S., Lee, D., Lindstad, H., Markowska, A. Z., Mjelde, A., Nelissen, D., Nilsen, J., Pålsson, C., Winebrake, J. J., Wu, W.-Q., and Yoshida, K.: Second IMO Greenhouse Gas Study 2009, Tech. rep., International Maritime Organization, London, UK, 2009.

Burkhardt, U. and Kärcher, B.: Global radiative forcing from contrail cirrus, Nat. Clim. Change, 1, 54-58, doi:10.1038/nclimate1068, 2011.

Capaldo, K., Corbett, J. J., Kasibhatla, P. S., Fischbeck, P., and Pandis, S. N.: Effects of ship emissions on sulphur cycling and radiative climate forcing over the ocean, Nature, 400, 743-746, doi:10.1038/23438, 1999.

Corbett, J. J., Fischbeck, P. S., and Pandis, S. N.: Global nitrogen and sulfur inventories for oceangoing ships, J. Geophys. Res., 104, 3457-3470, doi:10.1029/1998JD100040, 1999.

Corbett, J. J., Winebrake, J. J., Green, E. H., Kasibhatla, P. S., Eyring, V., and Lauer, A.: Mortality from ship emissions: a global assessment, Environ. Sci. Tech., 41, 8512-8518, doi:10.1021/es071686z, 2007.

Dentener, F., Kinne, S., Bond, T. C., Boucher, O., Cofala, J., Generoso, S., Ginoux, P., Gong, S. L., Hoelzemann, J. J., Ito, A., Marelli, L., Penner, J. E., Putaud, J.-P., Textor, C., Schulz, M., van Der Werf, G. R., and Wilson, J.: Emissions of primary aerosol and precursor gases in the years 2000 and 1750 prescribed data-sets for AeroCom, Atmos. Chem. Phys., 6, 43214344, doi:10.5194/acp-6-4321-2006, 2006.

Edgerton, E., Lavery, T., Hodges, M., and Bowser, J.: National dry deposition network: Second annual progress report, Tech. rep., Environmental Protection Agency, 1990.

Eyring, V., Isaksen, I. S. A., Berntsen, T., Collins, W., Corbett, J. J., Endresen, O., Grainger, R. G., Moldanova, J., Schlager, H., and Stevenson, D. S.: Transport impacts on atmosphere and climate: Shipping, Atmos. Environ., 44, 4735-4771, doi:10.1016/j.atmosenv.2009.04.059, 2010.

Fang, Y., Naik, V., Horowitz, L. W., and Mauzerall, D. L.: Air pollution and associated human mortality: the role of air pollutant emissions, climate change and methane concentration increases from the preindustrial period to present, Atmos. Chem. Phys., 13, 1377-1394, doi:10.5194/acp-13-1377-2013, 2013.

Fortuin, J. P. F. and Kelder, H. M.: An ozone climatology based on ozonesonde and satellite measurements, J. Geophys. Res., 103, 31709-31734, doi:10.1029/1998JD200008, 1998.

Fuglestvedt, J., Berntsen, T., Eyring, V., Isaksen, I. S. A., Lee, D. S., and Sausen, R.: Shipping emissions: from cooling to warming of climate and reducing impacts on health, Environ. Sci. Tech., 43, 9057-9062, doi:10.1021/es901944r, 2009.

Fuglestvedt, J. S., Berntsen, T., Myhre, G., Rypdal, K., and Skeie, R. B.: Climate forcing from the transport sectors, P. Natl. Acad. Sci. Unit. States Am., 105, 454-458, doi:10.1073/pnas.0702958104, 2008.

Fuglestvedt, J. S., Shine, K. P., Berntsen, T., Cook, J., Lee, D. S., Stenke, A., Skeie, R. B., Velders, G. J. M., and Waitz, I. A.: Transport impacts on atmosphere and climate: Metrics, Atmos. Environ., 44, 4648-4677, doi:10.1016/j.atmosenv.2009.04.044, 2010.

Gettelman, A. and Chen, C.: The climate impact of aviation aerosols, Geophys. Res. Lett., 40, 2785-2789, doi:10.1002/grl.50520, 2013.

Grewe, V.: A generalized tagging method, Geosci. Model Dev., 6, 247-253, doi:10.5194/gmd-6-247-2013, 2013.

Grewe, V., Tsati, E., and Hoor, P.: On the attribution of contributions of atmospheric trace gases to emissions in atmospheric model applications, Geosci. Model Dev., 3, 487-499, doi:10.5194/gmd3-487-2010, 2010.

Guelle, W., Schulz, M., Balkanski, Y., and Dentener, F.: Influence of the source formulation on modeling the atmospheric global distribution of sea-salt aerosol, J. Geophys. Res., 106, 27509 27524, 2001.

Guenther, A., Hewitt, C. N., Erickson, D., Fall, R., Geron, C., Graedel, T., Harley, P., Klinger, L., Lerdau, M., Mckay, W. A., Pierce, T., B, S., Steinbrecher, R., Tallamraju, R., Taylor, J., and Zimmerman, P.: A global model of natural volatile organic compound emissions, J. Geophys. Res., 100, 8873-8892, doi:10.1029/94JD02950, 1995.

Hand, J. L., Copeland, S. A., Day, D. E., Dillner, A. M., Indresand, H., Malm, W. C., McDade, C. E., Moore Jr., C. T., Pitchford, M. A., Schichtel, B. A., and Watson, J. G.: Spatial and seasonal patterns and temporal variability of hazeand its constituents in the United States, Tech. rep., Interagency Monitoring of Protected Visual Environments, 2011.

Hendricks, J., Kärcher, B., Döpelheuer, A., Feichter, J., Lohmann, U., and Baumgardner, D.: Simulating the global atmospheric black carbon cycle: a revisit to the contribution of aircraft emissions, Atmos. Chem. Phys., 4, 2521-2541, doi:10.5194/acp-42521-2004, 2004.

Hendricks, J., Kärcher, B., and Lohmann, U.: Effects of ice nuclei on cirrus clouds in a global climate model, J. Geophys. Res., 116, 1-24, doi:10.1029/2010JD015302, 2011.

Hjellbrekke, A.-G. and Fjæraa, A. M.: Acidifying and eutrophying compounds and particulate matter, Tech. rep., Norwegian Meteorological Institute, 2011.

Hodnebrog, O., Berntsen, T. K., Dessens, O., Gauss, M., Grewe, V., Isaksen, I. S. A., Koffi, B., Myhre, G., Olivié, D., Prather, M. J., Stordal, F., Szopa, S., Tang, Q., van Velthoven, P., and Williams, J. E.: Future impact of traffic emissions on atmospheric 
ozone and $\mathrm{OH}$ based on two scenarios, Atmos. Chem. Phys., 12, 12211-12225, doi:10.5194/acp-12-12211-2012, 2012.

Holben, B. N., Eck, T. F., Slutsker, I., Tanre, D., Buis, J. P., Setxer, A., Vermote, E., Reagan, J. A., Kaufman, Y. J., Nakajima, T., Lavenu, F., Jankowiak, I., and Smirnov, A.: AERONET - A federated instrument network and data archive for aerosol characterization, Rem. Sens. Environ., 16, 1-16, doi:10.1016/S00344257(98)00031-5, 1998a.

Holben, B. N., Tanré, D., Smirnov, A., Eck, T. F., Slutsker, I., Abuhassan, N., Newcomb, W. W., Schafer, J. S., Chatenet, B., Lavenu, F., Kaufman, Y. J., Vande Castle, J., Setzer, A., Markham, B., Clark, D., Frouin, R., Halthore, R., Karneli, A., O’Neill, N. T., Pietras, C., Pinker, R. T., Voss, K., and Zibordi, G.: An emerging ground-based aerosol climatology: Aerosol optical depth from AERONET, J. Geophys. Res., 106, 1206712097, doi:10.1029/2001JD900014, 1998b.

Hoor, P., Caro, D., Dessens, O., Endresen, O., Gauss, M., Grewe, V., Hauglustaine, D. A., Isaksen, I. S. A., Lelieveld, J., Myhre, G., Meijer, E., Olivie, D., Prather, M. J., Schnadt Poberaj, C., Shine, K. P., Staehelin, J., Tang, Q., van Aardenne, J. A., van Velthoven, P., and Sausen, R.: The impact of traffic emissions on atmospheric ozone and OH: results from QUANTIFY, Atmos. Chem. Phys., 9, 3113-3136, doi:10.5194/acp-9-3113-2009, 2009.

Jeuken, A. B. M., Siegmund, P. C., Heijboer, L. C., Feichter, J., and Bengtsson, L.: On the potential of assimilating meteorological analyses in a global climate model for the purpose of model validation, J. Geophys. Res., 101, 16939-16950, doi:10.1029/96JD01218, 1996.

Jöckel, P., Tost, H., Pozzer, A., Brühl, C., Buchholz, J., Ganzeveld, L. N., Hoor, P., Kerkweg, A., Lawrence, M. G., Sander, R., Steil, B., Stiller, G., Tanarhte, M., Taraborrelli, D., van Aardenne, J. A., and Lelieveld, J.: The atmospheric chemistry general circulation model ECHAM5/MESSy1: consistent simulation of ozone from the surface to the mesosphere, Atmos. Chem. Phys., 6, 50675104, doi:10.5194/acp-6-5067-2006, 2006.

Jurkat, T., Voigt, C., Arnold, F., Schlager, H., Kleffmann, J., Aufmhoff, H., Schäuble, D., Schaefer, M., and Schumann, U.: Measurements of $\mathrm{HONO}, \mathrm{NO}, \mathrm{NO}_{\mathrm{y}}$ and $\mathrm{SO}_{2}$ in aircraft exhaust plumes at cruise, Geophys. Res. Lett., 38, 1-5, doi:10.1029/2011GL046884, 2011.

Kahn Ribeiro, S., Kobayashi, S., Beuthe, M., Gasca, J., Greene, D., Lee, D., Muromachi, Y., Newton, P., Plotkin, S., Sperling, D., Wit, R., and Zhou, P.: Transport and its infrastructure, in: Climate Change 2007: Mitigation. Contribution of Working Group III to the Fourth Assessment Report of the Intergovernmental Panel on Climate Change, IPCC, edited by: Metz, B., Davidson, O., Bosch, P., Dave, R., and Meyer, L., 323-385, Cambridge University Press, Cambridge, United Kingdom and New York, NY, USA, 2007.

Kärcher, B., Möhler, O., Demott, P. J., Pechtl, S., and Yu, F.: Insights into the role of soot aerosols in cirrus cloud formation, Atmos. Chem. Phys., 7, 4203-4227, doi:10.5194/acp-7-4203-2007, 2007.

Kerkweg, A., Buchholz, J., Ganzeveld, L., Pozzer, A., Tost, H., and Jöckel, P.: Technical Note: An implementation of the dry removal processes DRY DEPosition and SEDImentation in the Modular Earth Submodel System (MESSy), Atmos. Chem. Phys., 6, 4617-4632, doi:10.5194/acp-6-4617-2006, 2006a.
Kerkweg, A., Sander, R., Tost, H., and Jöckel, P.: Technical Note: Implementation of prescribed (OFFLEM), calculated (ONLEM), and pseudo-emissions (TNUDGE) of chemical species in the Modular Earth Submodel System (MESSy), Atmos. Chem. Phys., 6, 3603-3609, doi:10.5194/acp-6-3603-2006, 2006 b.

Koffi, B., Szopa, S., Cozic, A., Hauglustaine, D. A., and van Velthoven, P.: Present and future impact of aircraft, road traffic and shipping emissions on global tropospheric ozone, Atmos. Chem. Phys., 10, 11681-11705, doi:10.5194/acp-1011681-2010, 2010.

Köhler, I., Dameris, M., Ackermann, I. J., and Hass, H.: Contribution of road traffic emissions to the atmospheric black carbon burden in the mid-1990s, J. Geophys. Res., 106, 17997-18014, doi:10.1029/2001JD900212, 2001.

Lamarque, J.-F., Bond, T. C., Eyring, V., Granier, C., Heil, A., Klimont, Z., Lee, D. S., Liousse, C., Mieville, A., Owen, B., Schultz, M. G., Shindell, D. T., Smith, S. J., Stehfest, E., van Aardenne, J. A., Cooper, O. R., Kainuma, M., Mahowald, N., McConnell, J. R., Naik, V., Riahi, K., and van Vuuren, D. P.: Historical (1850-2000) gridded anthropogenic and biomass burning emissions of reactive gases and aerosols: methodology and application, Atmos. Chem. Phys., 10, 7017-7039, doi:10.5194/acp10-7017-2010, 2010.

Lauer, A., Hendricks, J., Ackermann, I. J., Schell, B., Hass, H., and Metzger, S.: Simulating aerosol microphysics with the ECHAM/MADE GCM - Part I: Model description and comparison with observations, Atmos. Chem. Phys., 5, 3251-3276, doi:10.5194/acp-5-3251-2005, 2005.

Lauer, A., Eyring, V., Hendricks, J., Jöckel, P., and Lohmann, U.: Global model simulations of the impact of ocean-going ships on aerosols, clouds, and the radiation budget, Atmos. Chem. Phys., 7, 5061-5079, doi:10.5194/acp-7-5061-2007, 2007.

Lee, D. S., Owen, B., Graham, A., Fichter, C., Lim, L. L., and Dimitriu, D.: Allocation of international aviation emissions from scheduled air traffic - Present day and historical (Report 2 of 3), Tech. rep., Manchester Metropolitan University, Centre for Air Transport and the Environment, 2005.

Lee, D. S., Fahey, D. W., Forster, P. M., Newton, P. J., Wit, R. C. N., Lim, L. L., Owen, B., and Sausen, R.: Aviation and global climate change in the 21st century, Atmos. Environ., 43, 35203537, doi:10.1016/j.atmosenv.2009.04.024, 2009.

Lee, D. S., Fahey, D. W., Forster, P. M., Newton, P. J., Wit, R. C. N., Lim, L. L., Owen, B., and Sausen, R.: Transport impacts on atmosphere and climate: Aviation, Atmos. Environ., 44, 46784734, doi:10.1016/j.atmosenv.2009.06.005, 2010.

Liu, X., Penner, J. E., and Wang, M.: Influence of anthropogenic sulfate and black carbon on upper tropospheric clouds in the NCAR CAM3 model coupled to the IMPACT global aerosol model, J. Geophys. Res., 114, D03204, doi:10.1029/2008JD010492, 2009.

Lohmann, U.: Possible aerosol effects on ice clouds via contact nucleation, J. Atmos. Sci., 59, 647-656, doi:10.1175/15200469(2001)059<0647:PAEOIC>2.0.CO;2, 2002.

Lohmann, U. and Feichter, J.: Global indirect aerosol effect: a review, Atmos. Chem. Phys., 5, 715-737, doi:10.5194/acp-5-7152005, 2005.

Lohmann, U., Feichter, J., Chuang, C. C., and Penner, J. E.: Prediction of the number of cloud droplets in the ECHAM GCM, 
J. Geophys. Res., 104, 9169-9198, doi:10.1029/1999JD900046, 1999.

Metzger, S., Dentener, F., Pandis, S. N., and Lelieveld, J.: Gas/aerosol partitioning: 1. A computationally efficient model, J. Geophys. Res., 107, 1-24, doi:10.1029/2001JD001102, 2002.

Moss, R. H., Edmonds, J. A., Hibbard, K. A., Manning, M. R., Rose, S. K., van Vuuren, D. P., Carter, T. R., Emori, S., Kainuma, M., Kram, T., Meehl, G. A., Mitchell, J. F. B., Nakicenovic, N., Riahi, K., Smith, S. J., Stouffer, R. J., Thomson, A. M., Weyant, J. P., and Wilbanks, T. J.: The next generation of scenarios for climate change research and assessment., Nature, 463, 747-756, doi:10.1038/nature08823, 2010.

Myhre, G., Shine, K. P., Rädel, G., Gauss, M., Isaksen, I. S. A., Tang, Q., Prather, M. J., Williams, J. E., van Velthoven, P., Dessens, O., Koffi, B., Szopa, S., Hoor, P., Grewe, V., Borken-Kleefeld, J., Berntsen, T. K., and Fuglestvedt, J. S.: Radiative forcing due to changes in ozone and methane caused by the transport sector, Atmos. Environ., 45, 387-394, doi:10.1016/j.atmosenv.2010.10.001, 2011.

Olivié, D. J. L., Cariolle, D., Teyssèdre, H., Salas, D., Voldoire, A., Clark, H., Saint-Martin, D., Michou, M., Karcher, F., Balkanski, Y., Gauss, M., Dessens, O., Koffi, B., and Sausen, R.: Modeling the climate impact of road transport, maritime shipping and aviation over the period 1860-2100 with an AOGCM, Atmos. Chem. Phys., 12, 1449-1480, doi:10.5194/acp-12-1449-2012, 2012.

Peters, K., Stier, P., Quaas, J., and Graß 1, H.: Aerosol indirect effects from shipping emissions: sensitivity studies with the global aerosol-climate model ECHAM-HAM, Atmos. Chem. Phys., 12, 5985-6007, doi:10.5194/acp-12-5985-2012, 2012.

Petzold, A., Döpelheuer, A., Brock, C. A., and Schröder, F.: In situ observations and model calculations of black carbon emission by aircraft at cruise altitude, J. Geophys. Res., 104, 22171-22181, doi:10.1029/1999JD900460, 1999.

Petzold, A., Hasselbach, J., Lauer, P., Baumann, R., Franke, K., Weingartner, E., Gurk, C., and Schlager, H.: Experimental studies on particle emissions from cruising ship, their characteristic properties, transformation and atmospheric lifetime in the marine boundary layer, Atmos. Chem. Phys., 8, 2387-2403, doi:10.5194/acp-8-2387-2008, 2008.

Pozzer, A., Jöckel, P., and Van Aardenne, J.: The influence of the vertical distribution of emissions on tropospheric chemistry, Atmos. Chem. Phys., 2, 961-987, doi:10.5194/acp-12-961-2012, 2009.

Pozzer, A., de Meij, A., Pringle, K. J., Tost, H., Doering, U. M., van Aardenne, J., and Lelieveld, J.: Distributions and regional budgets of aerosols and their precursors simulated with the EMAC chemistry-climate model, Atmos. Chem. Phys., 12, 961-987, doi:10.5194/acp-12-961-2012, 2012.

Pringle, K. J., Tost, H., Metzger, S., Steil, B., Giannadaki, D., Nenes, A., Fountoukis, C., Stier, P., Vignati, E., and Lelieveld, J.: Description and evaluation of GMXe: a new aerosol submodel for global simulations (v1), Geosci. Model Dev., 3, 391-412, doi:10.5194/gmd-3-391-2010, 2010.

Prinn, R. G., Weiss, R. F., Fraser, P. J., Simmonds, P. G., Cunnold, D. M., Alyea, F. N., Doherty, S. O., Salameh, P., Miller, B. R., Huang, J., Wang, R. H. J., Hartley, D. E., Harth, C., Steele, L. P., Sturrock, G., Midgley, P. M., and McCulloch, A.: A history of chemically and radiatively important gases in air deduced from
ALE/GAGE/AGAGE, J. Geophys. Res., 105, 17 751-17 792, doi:10.1029/2000JD900141, 2000.

Pye, H. O. T., Liao, H., Wu, S., Mickley, L. J., Jacob, D. J., Henze, D. K., and Seinfeld, J. H.: Effect of changes in climate and emissions on future sulfate-nitrate-ammonium aerosol levels in the United States, J. Geophys. Res., 114, D01205, doi:10.1029/2008JD010701, 2009.

Righi, M., Klinger, C., Eyring, V., Hendricks, J., Lauer, A., and Petzold, A.: Climate impact of biofuels in shipping: global model studies of the aerosol indirect effect, Environ. Sci. Tech., 45, 3519-3525, doi:10.1021/es1036157, 2011.

Roeckner, E., Brokopf, E., Esch, M., Giorgetta, M. A., Hagema, S., and Kornblueh, L.: Sensitivity of simulated climate to horizontal and vertical resolution in the ECHAM5 atmosphere model, J. Clim., 19, 3771-3791, doi:10.1175/JCLI3824.1, 2006.

Sander, R., Kerkweg, A., Jöckel, P., and Lelieveld, J.: Technical Note: The new comprehensive atmospheric chemistry module MECCA, Atmos. Chem. Phys., 5, 445-450, doi:10.5194/acp-5445-2005, 2005.

Santese, M., Perrone, M. R., Zakey, A. S., De Tomasi, F., and Giorgi, F.: Modeling of Saharan dust outbreaks over the Mediterranean by RegCM3: case studies, Atmos. Chem. Phys., 10, 133156, doi:10.5194/acp-10-133-2010, 2010.

Sausen, R.: Transport impacts on atmosphere and climate, Atmos. Environ., 44, 4646-4647, doi:10.1016/j.atmosenv.2010.02.033, 2010.

Sausen, R., Isaksen, I., Grewe, V., Hauglustaine, D., Lee, D. S., Myhre, G., Köhler, M. O., Pitari, G., Schumann, U., Stordal, F., and Zerefos, C.: Aviation radiative forcing in 2000: An update on IPCC (1999), Meteorol. Z., 14, 555-561, doi:10.1127/09412948/2005/0049, 2005.

Sausen, R., Gierens, K., Eyring, V., Hendricks, J., and Righi, M.: Climate impact of transport, in: Atmospheric Physics. Background - Methods - Trends, edited by: Schumann, U., Springer, Berlin, Heidelberg, Germany,711-725, 2012.

Schulz, M., Textor, C., Kinne, S., Balkanski, Y., Bauer, S. E., Berntsen, T., Berglen, T. F., Boucher, O., Dentener, F., Guibert, S., Isaksen, I. S. A., Iversen, T., Koch, D. M., Kirkevåg, A., Liu, X., Montanaro, V., Myhre, G., Penner, J. E., Pitari, G., Reddy, M. S., Seland, O., Stier, P., and Takemura, T.: Radiative forcing by aerosols as derived from the AeroCom present-day and pre-industrial simulations, Atmos. Chem. Phys., 6, 5225-5246, doi:10.5194/acp-6-5225-2006, 2006.

Seinfeld, J. H. and Pandis, S. N.: Atmospheric chemistry and physics, John Wiley \& Sons, New York, US, 1998.

Skeie, R. B., Fuglestvedt, J. S., Berntsen, T., Lund, M. T., Myhre, G., and Rypdal, K.: Global temperature change from the transport sectors: Historical development and future scenarios, Atmos. Environ., 43, 6260-6270, doi:10.1016/j.atmosenv.2009.05.025, 2009.

Spiro, P. A., Jacob, D. J., and Logan, J. A.: Global inventory of sulfur emissions with $1^{\circ} \times 1^{\circ}$ resolution, J. Geophys. Res., 97, 6023-6036, doi:10.1029/91JD03139, 1992.

Tost, H., Jöckel, P., Kerkweg, A., Sander, R., and Lelieveld, J.: Technical Note: A new comprehensive SCAVenging submodel for global atmospheric chemistry modelling, Atmos. Chem. Phys., 6, 565-574, doi:10.5194/acp-6-565-2006, 2006.

Totsuka, T., Sase, H., and Shimizu, H.: Major activities of acid deposition monitoring network in East Asia (EANET) and related 
studies, in: Plant Responses to Air Pollution and Global Change, edited by: Omasa, K., Nouchi, I., and DeKok, L. J., SpringerVerlag Tokyo, 251-259, doi:10.1007/4-431-31014-2_28, 2005.

Twomey, S.: The influence of pollution on the shortwave albedo of clouds, J. Atmos. Sci., 34, 1149-1152, doi:10.1175/15200469(1977)034<1149:TIOPOT>2.0.CO;2, 1977.

Uherek, E., Halenka, T., Borken-Kleefeld, J., Balkanski, Y., Berntsen, T., Borrego, C., Gauss, M., Hoor, P., Juda-Rezler, K., and Lelieveld, J.: Transport impacts on atmosphere and climate: Land transport, Atmos. Environ., 44, 4772-4816, doi:10.1016/j.atmosenv.2010.01.002, 2010.

Unger, N.: Global climate impact of civil aviation for standard and desulfurized jet fuel, Geophys. Res. Lett., 38, 1-6, doi:10.1029/2011GL049289, 2011.
Unger, N., Zhao, Y., and Dang, H.: Mid-21st century chemical forcing of climate by the civil aviation sector, Geophys. Res. Lett., 40, 641-645, doi:10.1002/grl.50161, 2013.

von Kuhlmann, R., Lawrence, M. G., Crutzen, P. J., and Rasch, P. J.: A model for studies of tropospheric ozone and nonmethane hydrocarbons: Model description and ozone results, J. Geophys. Res., 108, 4294, doi:10.1029/2002JD002893, 2003.

Wang, C., Corbett, J. J., and Firestone, J.: Improving spatial representation of global ship emissions inventories, Environ. Sci. Tech., 42, 193-199, doi:10.1021/es0700799, 2007.

Winebrake, J. J., Corbett, J. J., Green, E. H., Lauer, A., and Eyring, V.: Mitigating the health impacts of pollution from oceangoing shipping: An assessment of low-sulfur fuel mandates, Environ. Sci. Tech., 43, 4776-4782, doi:10.1021/es803224q, 2009. 